\title{
History of the Dalian Institute of Chemical Physics and the Friendship between China and Japan in catalysis
}

\author{
S. Ted Oyama a,b,* with \\ Qin Xin c, Guoxing Xiong c, Wenjie Shen c, Jie Xu c, Hongmei Yin c, Youzhu Yuan d, Haichao Liu e, Huidong Zheng a \\ a School of Chemical Engineering, Fuzhou University, Fuzhou 350108, Fujian, China \\ b The University of Tokyo, 7-3-1 Hongo, Bunkyo-ku, Tokyo 113-8656, Japan \\ c Dalian Institute of Chemical Physics, Chinese Academy of Sciences, Dalian 116023, Liaoning, China \\ d State Key Laboratory of Physical Chemistry of Solid Surfaces, iChEM, National Engineering Laboratory for Green Chemical Productions of \\ Alcohols-Ethers-Esters, College of Chemistry and Chemical Engineering, Xiamen University, Xiamen 361005, Fujian, China \\ e Beijing National Laboratory for Molecular Sciences, State Key Laboratory for Structural Chemistry of Unstable and Stable Species, College of Chemistry \\ and Molecular Engineering, Peking University, Beijing 100871, China
}

\section{A R T I C L E I N F O}

\section{Article history:}

Received 23 July 2019

Accepted 11 August 2019

Published 5 November 2019

\section{A B S T R A C T}

This article presents a history of the origins of the Dalian Institute of Chemical Physics, Chinese Academy of Sciences (Abbreviated as DICP) and relates the recent friendship between China and Japan in the field of catalysis. Although the official beginning of DICP is in 1949 with the birth of the People's Republic of China, there are earlier roots that went back to the defeat of Russia by Imperial Japan in 1905. This began a period of occupation and exploitation of Northest Asia by Japan which did not end until its defeat by Allied forces in 1945. During the period of occupation, a laboratory was created called the Central Research Laboratory of the South Manchurian Railroad Company, which was staffed by the best and brightest researchers from Japan, and was able to develop new processes in chemicals and synthetic fuels that fed the Japanese Imperial forces. Between 1945 and 1949, Dalian was administered by the Soviet Union, and the removable equipment from the Laboratory was taken. In this period one individual stood out, the Laboratory Director Marusawa Tsuneya, who risked his life to preserve the scientific records and staff of the institute, and then stayed in Dalian for ten years after the Second World War to help China rebuild its capabilities. The Central Research Laboratory is still preserved as the Old Campus of DICP.

The origin of the friendship between China and Japan in catalysis can be traced to Professor Morikawa Kiyoshi, who worked in the Central Research Laboratory and helped commercialize a shale coal liquefaction process. Upon his return to Japan he became Professor at the Tokyo Institute of Technology and in 1975 organized the first visit by Japanese academics to China. This was reciprocated in visits to Japan in 1977 and 1980 by top researchers such as Zhang Dayu, Min Enze, Tsai Khirui, Lu Jiaxi, and Lin Liwu. This resulted in numerous contacts between individuals, which multiplied geometrically. Notably among these were the personal interactions between Guo Xiexian, the Vice-Director of DICP and Tamaru Kenzi, a Professor at the University of Tokyo, which led to a friendship lasting decades and encompassing generations. In 1981, Guo Xiexian organized the first China-Japan-USA Symposium in Dalian, assisted by Tamaru Kenzi, which was attended by over 90 scientists. This meeting was a big success, and was to lead to the organization of many other multi-country conferences, further promoting exchanges. It culminated with the hosting of China of the $16^{\text {th }}$ International Congress on Catalysis in 2016 in Beijing, with Li Can as President.

Today DICP is a sprawling organization with over 1300 permanent staff, and is one of the powerhouses of catalysis in the world. From 2000, it has been led by Directors Bao Xinhe, Zhang Tao, and Liu Zhongmin. The Institute is making enormous contributions to research and producing cutting-edge technology, and its future is bright.

(C) 2019, Dalian Institute of Chemical Physics, Chinese Academy of Sciences. Published by Elsevier B.V. All rights reserved.

\footnotetext{
* Corresponding author. E-mail: oyama@vt.edu DOI: S1872-2067(19)63483-2 | http://www.sciencedirect.com/science/journal/18722067 | Chin. J. Catal., Vol. 40, No. 11, November 2019
} 


\section{The early history}

The year 2019 marks the $70^{\text {th }}$ anniversary of the founding of modern day China as well as the beginning of the Dalian Institute of Chemical Physics, Chinese Academy of Sciences (Abbreviated as DICP). But the inception of the Institute reaches further back than 1949. The early foundations will be briefly described in this paper, and then the development of Chinese-Japanese friendship in catalysis through the microcosm of individual lives. The story is far from comprehensive and concentrates on a few persons with whom the principal author is familiar.

Northeastern Asia in the early $20^{\text {th }}$ century was a region rich in natural resources [1]. This bounty was an irresistible lure for Russia, Japan and China [2]. As a result of Japan's victory in the Russo-Japanese War, in 1905 Japan acquired the rights of the Northeastern Asia south of the Amur river, including the Liaotung Peninsula (Current Chinese: Liaodong辽东半岛) and the island of Sakhalin [3]. Japan was an island nation poor in resources and the riches of Northeastern China were a boon for the country. Here would begin a long period of occupation, exploitation, and oppression. The Japanese built administration buildings, hospitals, monuments, schools, universities, roads, bridges, and railroads and installed electrical, water, and sewage systems [4]. It is said that the rapid development of this region of China after the Second World War was due to the infrastructure left by the Japanese. But the motives of the Japanese were not benevolent or altruistic. Much of the building that was done utilized the forced labor of thousands of coerced Chinese laborers under harsh conditions. The mines and factories that were built were not for the welfare of the local people but to enable the export of the riches of the land to Japan. Chinese schoolchildren were allowed to attend the schools, but they were treated as second-class citizens [4].

Among the assets obtained by the Japanese in 1905 was the railroad between Changchun (长春, Japanese: Choshun) and Dalian (Fig. 1) [5,6]. The railroad was an important means of transporting materials, goods, and people. In 1906, Japan established the South Manchurian Railway Company, at first a civilian organization. The Railway Company was to be headed by prominent politicians, the first of which was Goto Shimpei ( 後藤新平) (Fig. 2), who later became Mayor of Tokyo. Later, military men would take control.

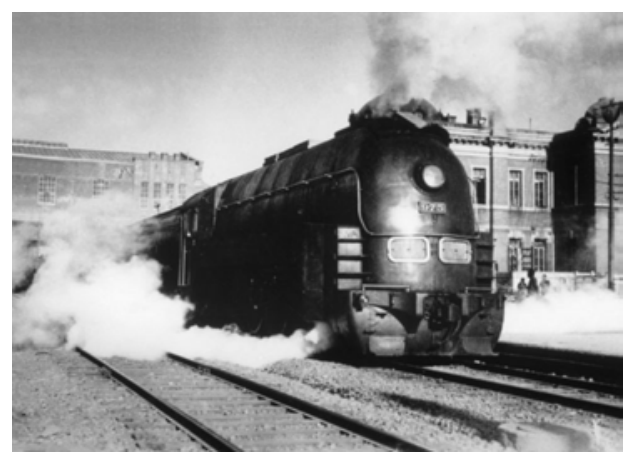

Fig. 1. Express train Asia [5] from Dalian to Changchun starts operation in 1934 [6].
The names and tenures of the presidents of the Railway Company are given in an account by Marusawa Tsuneya(丸沢 常哉) [6], a past director of the Central Research Laboratory. The South Manchurian Central Research Laboratory was founded in 1907 in Dalian at the tip of the Liaodong Peninsula as part of the Railway Company. The first Director of the Central Research Laboratory was Hiromatsu Syozaemon (廣松勝左 衛門). The Central Research Laboratory was the direct progenitor of what was to become the Dalian Institute of Chemical Physics (DICP), and the main building still stands as part of the DICP old campus (Fig. 3).

The book by Marusawa Tsuneya (丸沢常哉) [6] and others by Sugita Nozomu (杉田望) [7] and Mine Takeshi (峰毅) [8] documented that the laboratory was a serious enterprise. It was furbished with modern equipment and instrumentation and its staff comprised the highest levels of elite scientists and engineers. Indeed, the laboratory was able to develop large scale processes for minerals extraction, soybean oil manufacture, and coal gasification and liquefaction to fuels and chemicals. A list of the commercialized technologies was given in the book by Mine Takashi [8].

The South Manchurian Railway Company was a contributor to the Japanese Imperial Army (JIA) finances. It allowed the export of raw materials such as coal, iron and timber to Japan and the movement of finished goods into the Northeast Region. There were substantial numbers of Japanese entrepreneurs and settlers in the area. The Railway Company controlled the production of oil (derived from shale) and delivered it to the Japanese naval forces and then the army. According to an account by Liang Bo (梁波) [9], there were great efforts placed in the search for petroleum in Northeast China with many expeditions and wells ( $>1200)$ drilled, but the Japanese failed to discover the large field at Daqing (大庆油田) just north of Harbin. Morikawa Kiyoshi (森川清 1907-1984), a Professor at the Tokyo Institute of Technology explained that this was because the Japanese drilled to only $800 \mathrm{~m}$, while the Daqing field was at $>1200 \mathrm{~m}$. Liang also pointed out that the Japanese did not know the geology of the region.

The Central Research Laboratory (to become DICP) supported the chemical and extractive industries. One of the achievements of the Central Research Laboratory was the development of shale oil technology. Japan did not have shale oil, so the process had to develop from scratch. Although basic components such as distillation and storage were known from

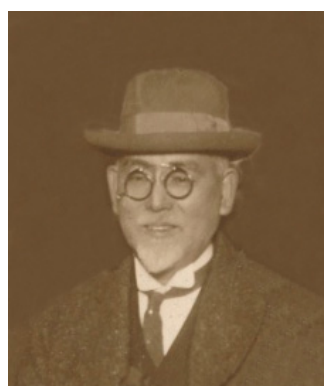

Fig. 2. Goto Shimpei (後藤新平), First President of the South Manchurian Railway Company. Photo credit: Tamaru family collection, Oyama Tamaru Hideko, Kamakura, Japan. 


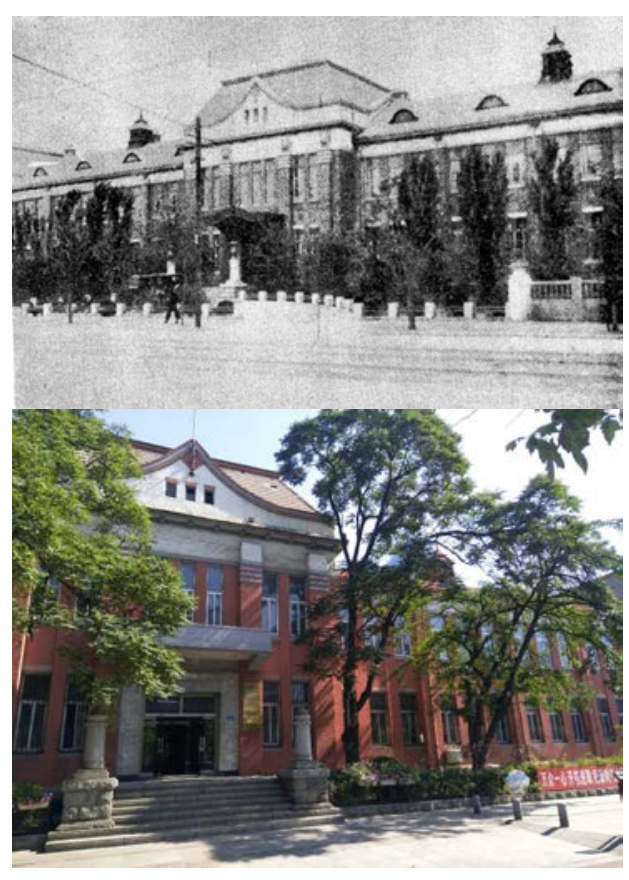

Fig. 3. Top: The South Manchurian Central Research Laboratory built in 1907 [7]; Bottom: The Old Campus of the Dalian Institute of Chemical Physics in 2019.

industrial developments in Scotland and the United States, the techniques for shale oil refining were invented by the technical staff and the machinery was built locally.

Although the Japanese had some early military victories by 1940 they were stretched thin over the vast Chinese countryside. Elsewhere, Japan was constrained by an oil embargo by the United States and in September 1940 signed the Tripartite Pact aligning itself with Germany and Italy. Increasing voices, including that of the Foreign Minister Matsuoka Yosuke, called for military action to gain supremacy in the Pacific Ocean and get access to oil supplies in the Dutch West Indies. This was resisted by Prime Minister Konoe, who advocated for peace, but was forced to resign in October 1941, to be replaced by Tojo Hideki. Six weeks later Japan carried out the infamous surprise attack on Pearl Harbor and drew the United States in to the Second World War. The purported objective was to unify the Far East under Japanese dominion in an Asian Co-Prosperity scheme. Despite some early successes in Singapore, Java, and Malaya (present day Malaysia), between 1942-1945 Japan would be defeated in major battles at Midway, Guadalcanal, Iwo Jima, the Philippines, Saipan, and Guam. In August 1945 the US dropped atomic bombs on the cities of Hiroshima and Nagasaki, effectively ending the Pacific War. At the Yalta Conference in February 1945 between Churchill, Stalin, and Roosevelt, it had been agreed by the Allies that on the defeat of Germany, Russia would declare war on Japan. Germany surrendered in May and in August 1945 Soviet forces attacked and quickly defeated the Kwantung Army and took control of Northeast China, Sakhalin and the Kuril Islands. Japan unconditionally surrendered to the Allies and the Soviet Union.

Between 1945 and 1949, Dalian was administered by the
USSR. The Japanese personnel of the Central Research Laboratory were allowed to leave freely, although some stayed. The equipment was taken away by the Russians at the end of the Second World War [8], but then was redeveloped by the Chinese with the assistance of Japanese staff who were retained after the war. In 1949, the Institute was a skeleton of its former self. As related by Marusawa Tsuneya, a former Laboratory Director during 1936-1939, the Central Research Laboratory had about 1000 people and in 1949 this became 80, including some women [6].

Marusawa Tsuneya (丸沢常哉, Fig. 4) was born on March 17, 1883, in Niigata Prefecture, Japan. In 1907 he graduated from the Applied Chemistry Department of the Tokyo Imperial University (University of Tokyo) at the top of his entire class. In 1909, he became associate Professor at the Kyushu Imperial University (Kyushu University) and then from 1911-1914 in Germany. He returned as a Professor and invented the Maruzawa-type sulfite pulp process, but was involved in the case of the Reclaimed Silver and retired in 1923. He became Professor at Lushun University of Technology, and returned in 1925 to become Professor and Dean of Engineering at Osaka University. In 1936 he was appointed Director of the Central Research Laboratory of the South Manchurian Railroad Company and served until 1940. In 1943, he was in charge of development in Manchuria as Chairman of the Chemical Industry Committee. In 1945, he was reappointed as Director of the Central Laboratory. After 1945, he remained in the Central Laboratory in Dalian and after working in Sichuan for one year, returned to Japan in 1955. He died on May 4, 1962 [10].

In an interview with Peking Broadcasting in 1955 [12], Marusawa explained that when Japan lost the war senior administrators in the South Manchurian Railroad Company directed that all documentation of the research be burned rather than be allowed to fall in the hands of the Soviets or the Chinese. As head of the Institute, Marusawa did not allow this as he felt that the research was a heritage of humanity. Later he expressed regrets for the actions of Japan in the Northeast and stayed on willingly in China to help its development. He was separated from his family during this time. He stated that despite the atrocities committed by the Japanese military, the Chinese people never showed any animosity to him, and they were kind. He returned to Japan in 1953 at the age of 70 .

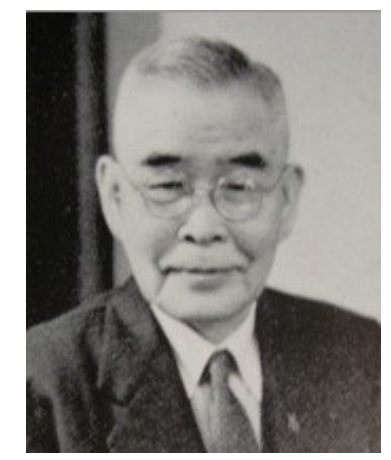

Fig. 4. Marusawa Tsuneya (丸沢常哉, 1883-1962). Photo from Ref. [11]. 
The Chinese government recognized the value of the Institute and paid the Soviet Union to obtain it [8]. Marusawa and ten others senior personnel were detained to help reestablish the Institute [6]. The first project assigned to the Central Research Laboratory was the production of potassium perchlorate, a component in explosives [6], in addition to the production of the pesticide DDT (dichlorodiphenyltrichloroethane) and pure ethanol.

\section{The foundation of the Institute}

\subsection{The Institute during 1949-1979}

The Dalian Institute of Chemical Physics was founded on the remnants of the South Manchurian Central Research Laboratory in March 1949. The Institute had different names at various times to accommodate its changing missions. It was initially called the Scientific Research Institute of Dalian University, with Qu Bochuan (屈伯川) as the first Director, and then in 1950 its name was changed to the Dalian Branch of the Northeastern Scientific Research Institute, with Dong Chen (董晨) as the second Director. In April 1952 it was renamed the Institute of Industrial Chemistry, at the same time becoming an Institute of the Chinese Academy of Sciences (CAS), and in November, Zhang Dayu (张大暗) was appointed the third Director. In 1954 it was converted to the Institute of Petroleum, reflecting the importance of oil resources. In 1958 the Research Divisions of Catalytic Chemistry, Analytical Chemistry and Lubricating Materials moved to Lanzhou to form the Lanzhou branch of the Institute of Petroleum. In 1962 the new Institute became the Lanzhou Institute of Chemical Physics, and the Dalian home organization became the Institute of Chemical Physics, due to a new emphasis on fundamental sciences. Finally, in 1970 the present name of Dalian Institute of Chemical Physics, CAS was adopted. The fourth Director of the Institute was Gu Yijian (顾 以健) in 1978 followed by Lou Nanquan (楼南泉) fifth Director in 1983, Zhang Cunhao (张存浩) sixth Director in 1986, Yuan Quan (袁权) seventh Director in 1990, Yang Boling (杨柏龄) eighth Director in 1994, Deng Maicun (邓麦村) ninth Director in 1998, Bao Xinhe (包信和) tenth Director in 2000, Zhang Tao (张涛), eleventh Director in 2007, and Liu Zhogmin (刘中民) twelfth and present Director.

Zhang Dayu was a strong leader of the Institute. In the 1950s, under the leadership of Zhang Dayu, students of the Institute went to the USSR to get advanced training. Other students from other academic institutions also were dispatched. As related by Xin Qin (辛勤) and Li Yongxue (李永学) [13], when these students came back they helped to teach catalysis in their universities, of which there were only three: Jilin University, Xiamen University, and Peking University. Most of the understanding at that time was based on Soviet knowledge such as semiconductor electronic theory, surface active groups, and Balandin's multiplet theory. In 1955, Zhang Dayu was inducted as an academician in the Chinese Academy of Sciences.

Zhang Dayu (张大显, Fig. 5) was born on January 15, 1906 in Jiangyin, Jiangsu Province, and was one of the pioneers of Chinese catalytic science. In 1929, Zhang Dayu graduated from

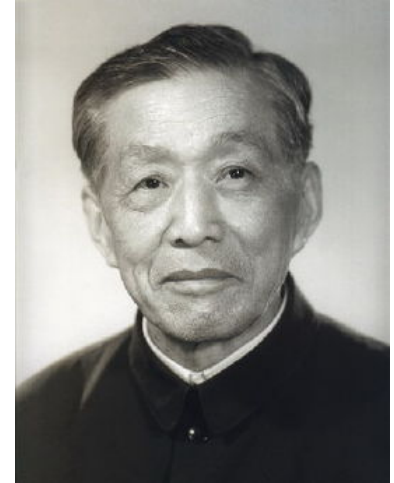

Fig. 5. Zhang Dayu (张大显, 1906-1989). Photo from Ref. [14].

Tsinghua University and went to Dresden University in Germany to study colloid and surface chemistry and received a doctorate in engineering in 1933. He returned to China to teach at Tsinghua University, where he served as a lecturer and Professor. In 1937 he taught at the National Southwest Associated University, and in 1945, he was a Professor at Jiaotong University and the head of the Department of Chemical Engineering at Tsinghua University in Beijing. In 1949, he was appointed as the Director of the Department of Chemical Engineering at Dalian University and a Researcher and Deputy Director at the Scientific Research Institute of Dalian University (former DICP) [14].

From 1952, the Scientific Research Institute of Dalian University became an Institute of the Chinese Academy of Sciences, and was renamed first the Institute of Industrial Chemistry, then Institute of Petroleum in 1954, the Institute of Chemical Physics in 1962, and the Dalian Institute of Chemical Physics in 1970. Zhang Dayu served as the Director from 1952 to 1968. From 1954 to 1967, Zhang Dayu also served as the first Director of the Shanxi Institute of Coal Chemistry of the Chinese Academy of Sciences. From 1958 to 1978, he served as the first Director of the Lanzhou Institute of Chemical Physics of the Chinese Academy of Sciences. In 1977, he was appointed consultant of the Institute of Photographic Chemistry of the Chinese Academy of Sciences. He died of an illness on February 20, 1989. Zhang Dayu was engaged in the research of colloidal chemistry and surface chemistry in the early years; in the early 1950s, he carried out research on the processing technology and chemical basics of petroleum, shale oil and coal; he led scientific research in the fields of catalysis, chromatography, chemical lasers and chemical engineering [14].

\subsection{Modern times (1980-present)}

China was to enter a period of rapid modernization in the areas of agriculture, industry, science/technology, and national defense in 1980. The drive to reform was accompanied by an impetus to open up the country to the outside world. In 1979 full diplomatic relations were established with the United States, and by 1980 many tourists were entering China [15].

The progress in catalysis in China from 1982 to 2012 is documented in a comprehensive review article by Xin Qin (辛 
勤) and Lin Liwu (林励吾) [16], which lists the leaders of all the major laboratories of catalysis in industry and academia and their achievements. In 1987, the State Key Laboratory of Catalysis within DICP was made operational with Guo Xiexian (郭炫 贤) as the first Laboratory Director (1987-1991), Xu Yide (徐奕 德) as the second Director (1992-1997), Li Can (李灿) as the third Director (1998-2005). Currently Shen Wenjie (申文杰) is the Director.

The Dalian Institute of Chemical Physics today is a major research organization with over 1300 staff members, 1000 graduate students, and 135 postdoctoral associates. It carries out research on catalytic chemistry, chemical engineering, molecular reaction dynamics, organic synthesis, and chromatography, all of which have furthered economic and technological development in China (Figs. 6-9).

\section{History of China-Japanese friendship in catalysis}

\subsection{Early exchanges (1975-1990)}

The most prominent individual from the Japanese side who can be credited with starting the long and fruitful exchange between Chinese and Japanese scientists in catalysis is Morikawa Kiyoshi (森川清), who was employed in the South Manchurian Central Research Laboratory during the Japanese occupation of the Northeast, and who remained in China for eight years after 1945. He brought a group of Japanese academics for a visit to Beijing in 1975, which planted the seeds for numerous subsequent exchanges.

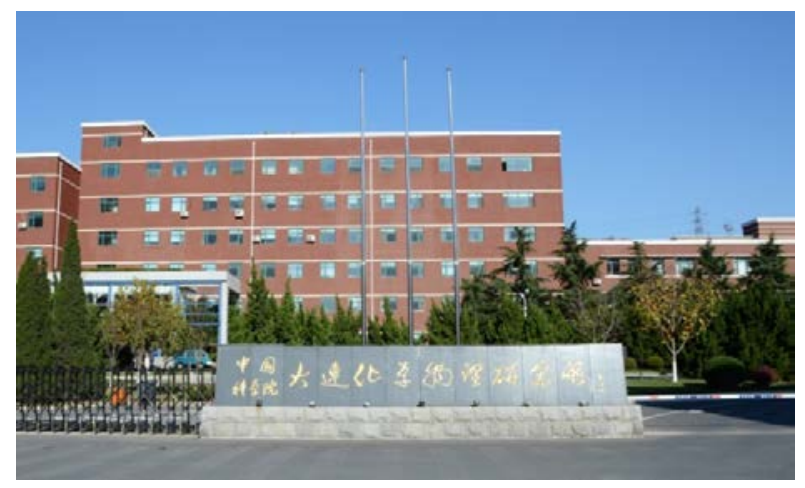

Fig. 6. DICP's main campus - the Xinghai Campus.

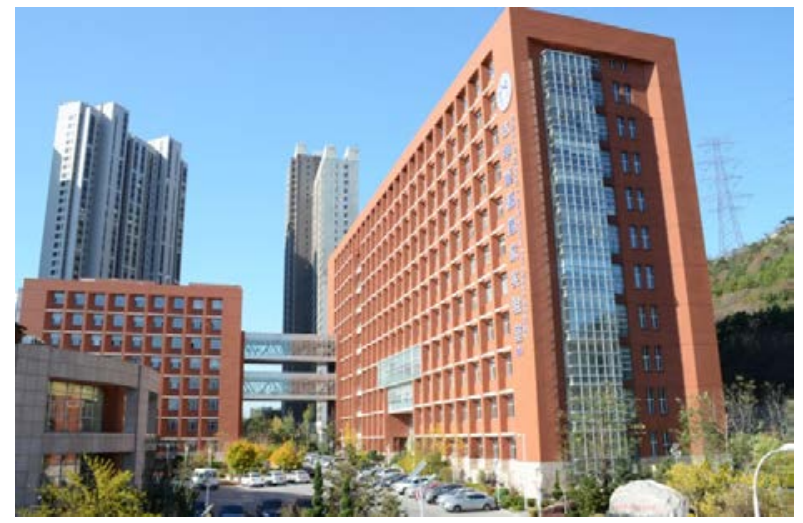

Fig. 7. The Energy Building at DICP.

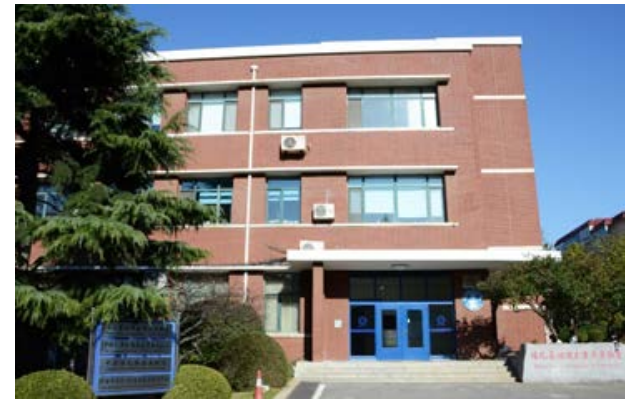

Fig. 8. The State Key Laboratory of Catalysis at DICP.

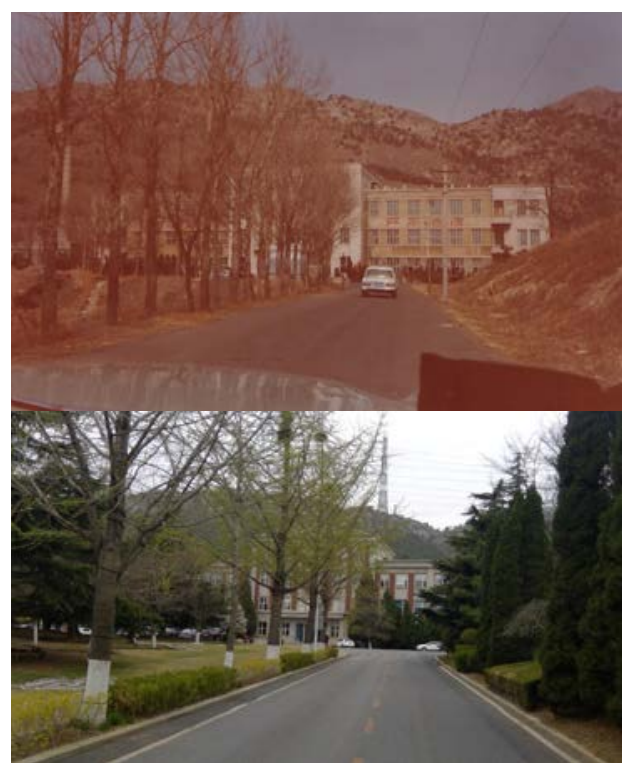

Fig. 9. Top: The Chemical Engineering Building at DICP in 1980 (Tamaru family collection). Bottom: the same building in 2019.

Morikawa Kiyoshi (森川清, Fig. 10) was born in Chiba, Japan on July 1, 1907 and graduated from the Tokyo High-School of Industrial Engineering in 1923, and then obtained his doctorate at Osaka University under the guidance of Prof. Chitani Toshizo (千谷利三) , following which he started work at the South Manchurian Central Research Laboratory. He married to Ozaki Kiyo (喜代) in 1931. In 1935-1936 he studied in the Graduate School at Princeton University, and then returned to the Central Research Laboratory and became chief of the synthetic fuel

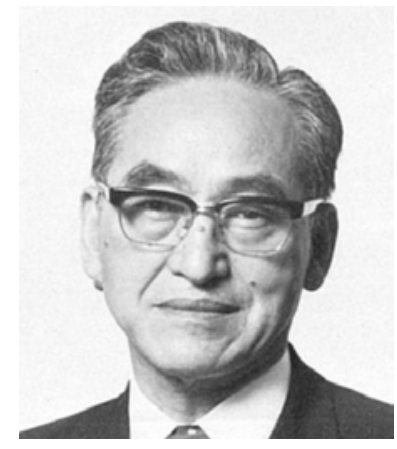

Fig. 10. Morikawa Kiyoshi (森川清, 1907-1984). Photo: Courtesy of Morikawa Akira. 


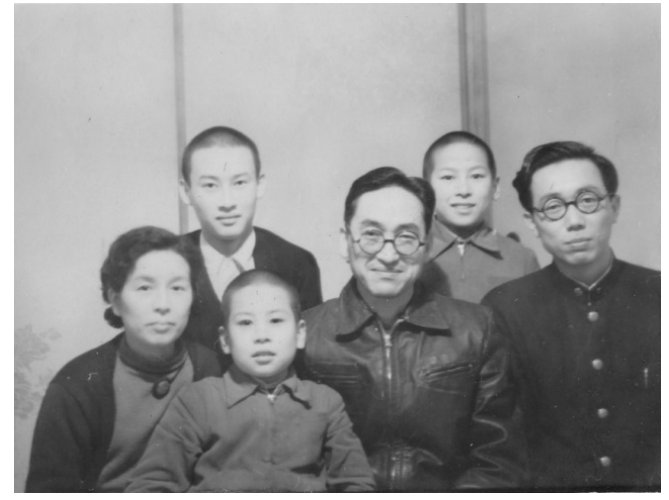

Fig. 11. Morikawa family and house guest in 1946. From left: Kiyo, Akira, Yasushi, Kiyoshi, Yutaka, Chen Hongfu (陈鸿福). Photo: Courtesy of Morikawa Akira.

laboratory and member of the Mantetsu Chemical Industry Committee. He was engaged in research on coal liquefaction, high-pressure hydrogen addition to shale oil, and plant construction.

Morikawa had three sons: the first (Akira, 阳) was born in Tokyo in 1937 and raised in Dalian, the second (Yutaka, 豊) was born in Dalian in 1942, and the third (Yasushi, 靖) was born in Dalian in 1944 [17]. In July 1945, he moved from Dalian to Changchun, still working in the South Manchurian Railway Co. He took a faculty position at Tohoku University in Changchun (presently Northeast Normal University, 东北师范大学). He also worked for a petrochemical company and helped build a fluid catalytic cracking plant. His family was repatriated in 1947 to Chiba, Japan where they had relatives, but Dr. Morikawa only returned to Japan in May 1953 [17]. He became Professor at the Tokyo Institute of Technology (TiTech) in September of the same year. At Titech (1957-1966), he was involved in acetonitrile synthesis at the Laboratory for Chemistry and Life Science, Institute of Innovative Research. After retiring from TiTech in 1968, he became Vice President and then Chairman ( 1968-1984) of the Japan Gas Company (Nikki, 日 挥), at present the most important engineering firm in Japan. For his numerous achievements he was awarded the Shiju Hosho medal in 1968. He passed away on January 1, 1984. Morikawa Hiroshi was a true friend of China and Japan. He spoke Chinese fluently and English fairly well (according to this author's memory). In 1946 in Changchun, his family hosted a Chinese student Chen Hongfu (陈鸿福) from Tohoku University in their family home (Fig. 11) [17].

In 1975, Prof. Morikawa organized the first major visit by Japanese academics to China, which became a key for future interactions (Figs. 12-14). The trip was on August 4-9 covering Beijing, Shanghai and Harbin. Included in the entourage were Tamaru Kenzi (田丸謙二) of the University of Tokyo, Tanabe Kozo (田部浩三) of Hokkaido University, Ozaki Atsumu (尾崎 萃) of the Tokyo Institute of Technology, Keii Tominaga (富長 慶伊) of the Tokyo Institute of Technology, Tarama Kimio (多羅 間公雄) of Kyoto University, and Kan Takao (菅孝男) of the University of Tokyo, School of Agriculture, all prominent catalysis researchers in Japanese universities. They visited principally Beijing.

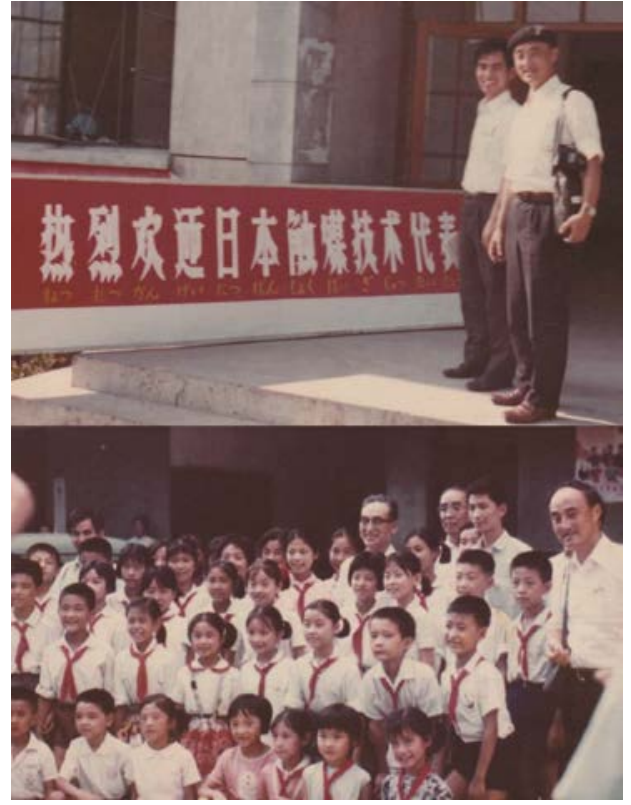

Fig. 12. Top: "Warmly welcome the delegation of catalysis technology from Japan” with unknown young man and Tamaru Kenzi (田丸謙二). Bottom: Delegates with schoolchildren. Back row from left: Morikawa Kiyoshi (多羅間公雄), Tarama Kimio (森川清), unknown young man, Tamaru Kenzi (田丸謙二).

The first meeting in 1975 helped to introduce Japanese scientists to China, and facilitated further exchanges. Notable is the case of Tamaru Kenzi who established a lifetime friendship with Guo Xiexian (Vice Director of DICP in 1978-1986). In

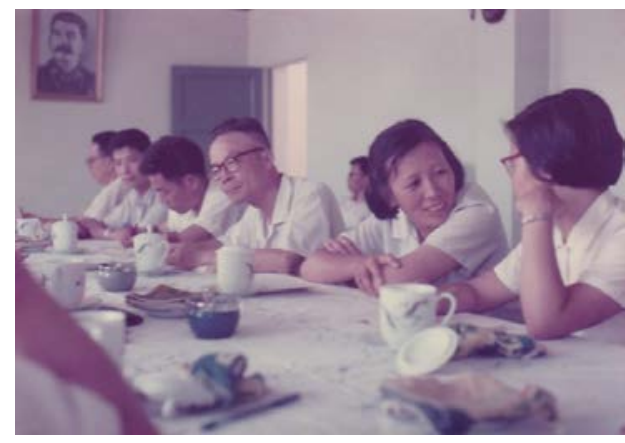

Fig. 13. Chinese scientists in meeting in Beijing in 1975.

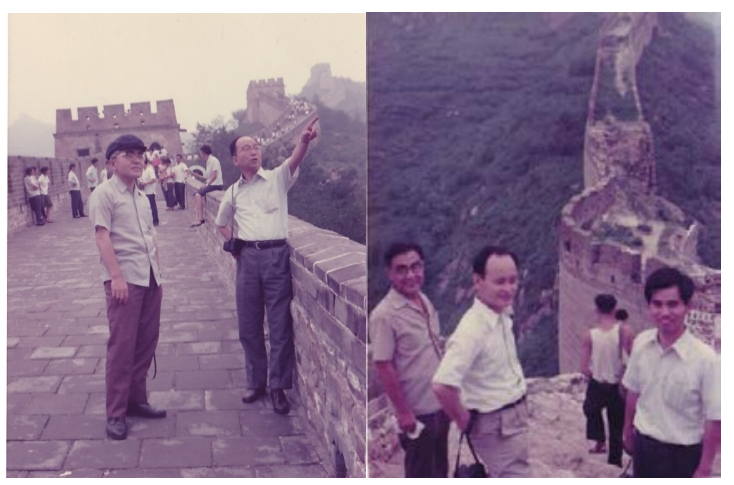

Fig. 14. Japanese delegation visiting Beijing at the Great Wall in 1975. Left: Tanabe Kozo (田部浩三) (left) and Ozaki Atsumu (尾崎萃) (right), Right: Chinese hosts (names unknown). 


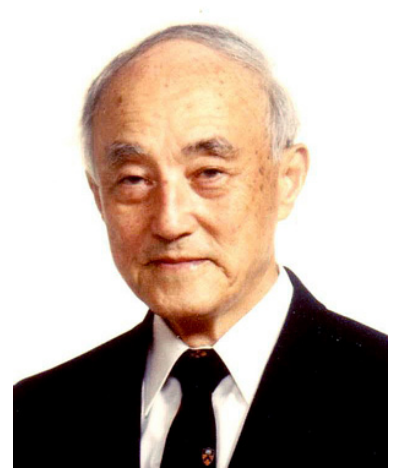

Fig. 15. Tamaru Kenzi (田丸謙二, 1923-). Photo credit: Tamaru family collection, Oyama Tamaru Hideko, Kamakura, Japan.

1979, Guo Xiexian arranged for a second visit of Tamaru to China, this time to teach a course on catalysis at the Lanzhou Institute of Chemical Physics, a sister institution to DICP.

Tamaru Kenzi (田丸謙二, Fig. 15) was born in Tokyo Japan in 1923, and was educated at the University of Tokyo, graduating in 1946, and received his Ph.D. in 1950 working on fire retardants under Samejima Jitsusaburo. He was a Professor at the University of Tokyo and an Honorary Professor at DICP. In 1951, he started as an Assistant Professor in the laboratory of Kinoshita at Yokohama National University where he studied electrochemistry. In 1953-1956, he received a Fulbright Fellowship to work with Sir Hugh Taylor at Princeton University. In Princeton, Tamaru studied the decomposition of germane and got the idea of the need to study catalysts at reaction conditions. When Tamaru told Prof. Taylor of this concept, he said "You are very ambitious", and he repeated this. Today, the need to study catalysts at in situ conditions is universally recognized and is applied regularly using spectroscopic and transient techniques.

In 1959, Tamaru joined the Faculty of Engineering, Yokohama National University, and in 1963 he became Professor in Department of Chemistry of the University of Tokyo. From 1981 to 1983, he served as Vice-President of the University. In 1984 after retiring from the University of Tokyo he joined the faculty of the Science University of Tokyo. From 1995 to 1999, he was Dean of the Yamaguchi campus of the Science University of Tokyo. Tamaru Kenzi held many important positions including the presidencies of the Catalysis Society of Japan in 1987, the Japan Chemical Society in 1989-1990, and the International Association of Catalysis Societies in 1988-1992. He was recognized with many awards, including the Japan Chemical Society Award in 1974, the Purple Agate (Shijuhosho, 紫綬 襄章) in 1985, the National Second Rank Treasure Trove Award (Kunnitou Zuihosho, 勲二等瑞宝章) in 1994, and the Japan Academy Award (Nihon Gakushiinsho, 日本学士院賞) in 2000.

In 1979, Tamaru Kenzi visited the Lanzhou Institute of Chemical Physics in a trip organized by Guo Xiexian (郭隻贤), which covered May 25 to June 8 and included Beijing and Shanghai. In Lanzhou, Tamaru gave a one-week course on catalysis by himself, and 200 participants came from 50 institutions (Figs. 16-19). This was the second of eighteen trips to China that would be setup by Guo Xiexian. The first visit to Beijing was in 1975. Tamaru was amazed at the very rapid im-

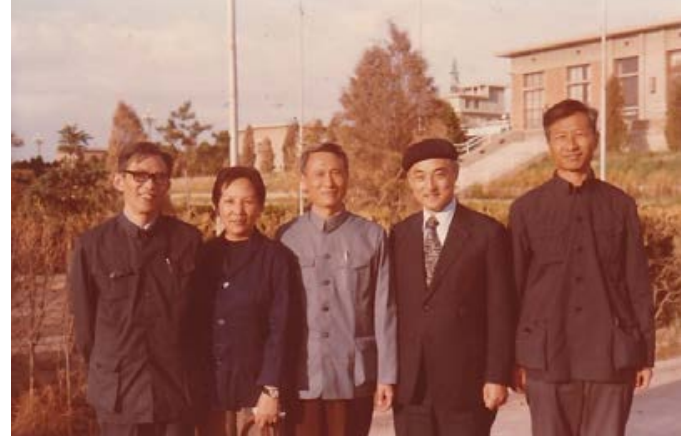

Fig. 16. Visit of Tamaru Kenzi to Lanzhou Institute of Chemical Physics in 1979. From left: Guo Xiexian (郭监贤), Japanese translator from Lanzhou University (she died in an airplane crash in the early 1980s), Jin Zhensheng (金振声, Vice Director of Lanzhou Institute of Chemical Physics), Tamaru Kenzi (田丸謙二), Sun Laicheng (孙来成, DICP). Photo Tamaru family collection.

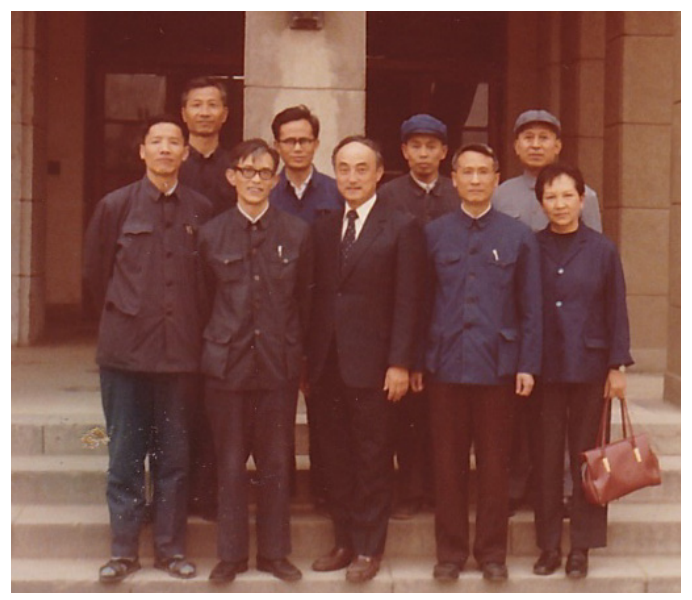

Fig. 17. Visit of Tamaru Kenzi to Lanzhou Institute of Chemical Physics in 1979. From left: Yin Yuangen (尹元根), Sun Laicheng (孙来成), Guo Xiexian (郭殓贤), Zhao Rongsheng (赵荣盛), Tamaru Kenzi (田丸謙二), Wang Yongcheng (王永成, Security Office person at Lanzhou Institute of Chemical Physics), Jin Zhensheng (金振声), Yu Yongzhong (于永忠, Solid Lubricant division of Lanzhou Institute of Chemical Physics), Japanese translator. Photo: Tamaru family collection.

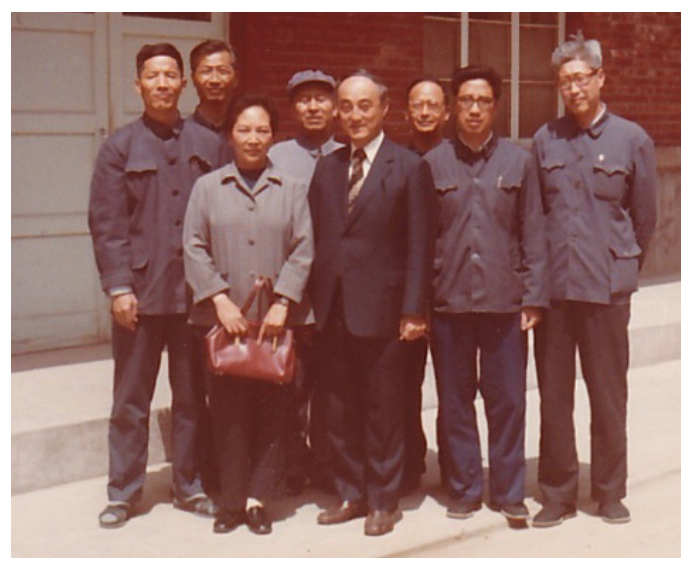

Fig. 18. Visit of Tamaru Kenzi to Lanzhou Institute of Chemical Physics in 1979. From left: Yin Yuangen (尹元根), Sun Laicheng (孙来成), Japanese translator, Yu Yongzhong (于永忠), Tamaru Kenzi (田丸謙二), Wang Zongshuo (王宗说, Catalysis division), Lin Liwu (林励吾, later elected as an academician), Lyu Yongan (吕永安). Photo: Tamaru family collection. 


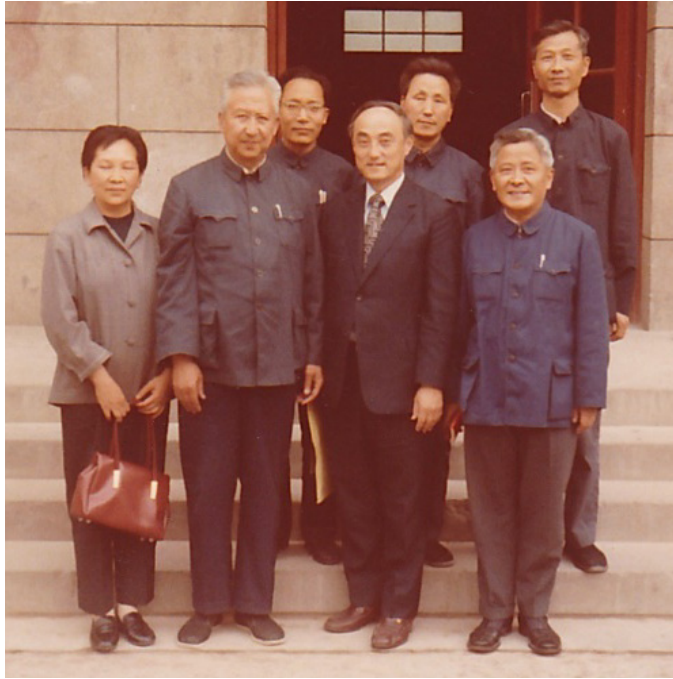

Fig. 19. Visit of Tamaru Kenzi to Lanzhou Institute of Chemical Physics, 1979. From left: translator, Lu Runlin (陆润林, Deputy Secretary of Lanzhou University), unknown person, Tamaru Kenzi (田丸謙二), Mr. Zhou (周先生, the Chairperson of Chemistry Department of Lanzhou University), Liu Youcheng (刘有成, later elected as an academician), Sun Laicheng (孙来成). Photo: Tamaru family collection.

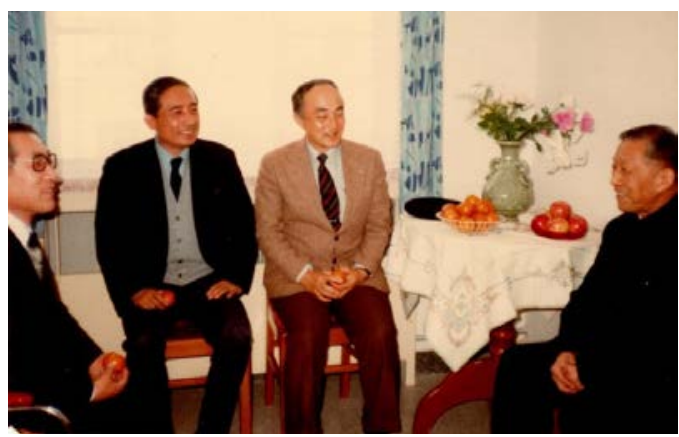

Fig. 20. Visit to Dalian in 1980. From left: Tanaka Nobuyuki (田中信行, inorganic chemist, an expert in metal complexes in Tohoku University), Mukaiyama Teruaki (向山光昭, organic chemist, University of Tokyo), Tamaru Kenzi (田丸謙二), Zhang Dayu (张大显, Director at DICP in 1952-1968). Photo: Tamaru family collection.

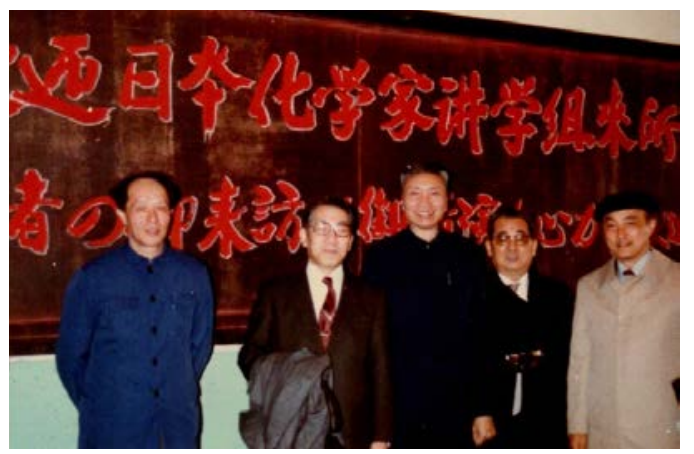

Fig. 21. Visit to Dalian in 1980. From left: Lou Nanquan (楼南泉, Director of DICP in 1983-1986), Tanaka Nobuyuki (田中信行), Gu Yijian (顾 以建, Director of DICP in 1978-1983), unknown possibly (Tamaru Kenzi, 狄原定司).

provement in the level of advancement since 1975. There were many questions on how to carry out research [18]. The remarks on China were published in Ref. [19].

In 1981, Tamaru Kenzi visited Beijing, Dalian, and Xiamen,

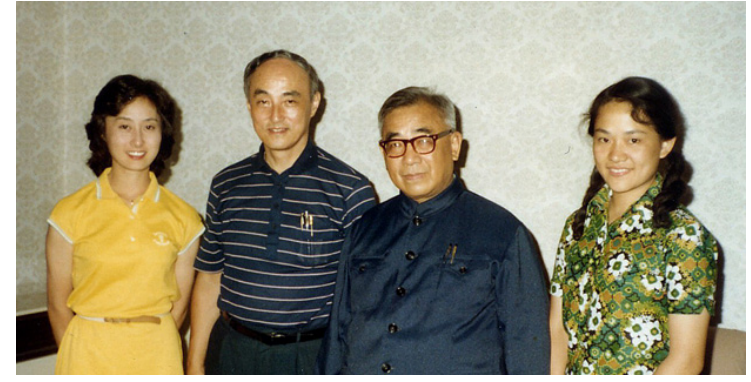

Fig. 22. Visit to Beijing in 1981. From left: Tamaru Hideko (田丸秀子), Tamaru Kenzi (田丸謙二), Lu Jiaxi (卢嘉锡, President of the Chinese Academy of Sciences), Lu Ziwei (卢紫莼). Photo: Tamaru family collection.

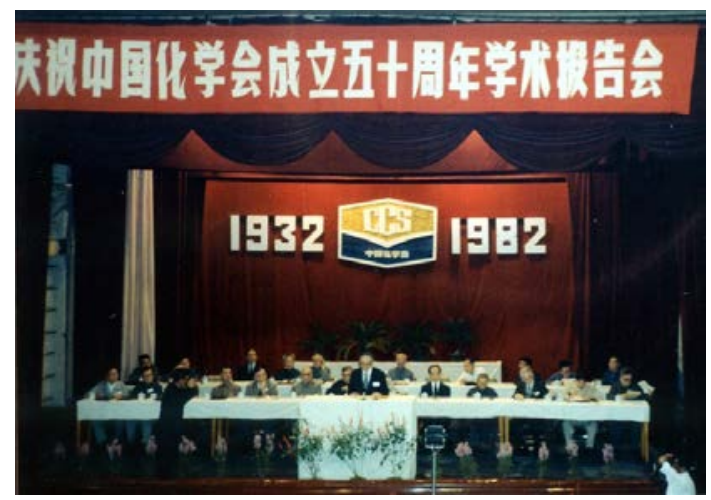

Fig. 23. Tamaru Kenzi (田丸謙二) addressed the Chinese Chemical Society on its $50^{\text {th }}$ anniversary in Nanjing.

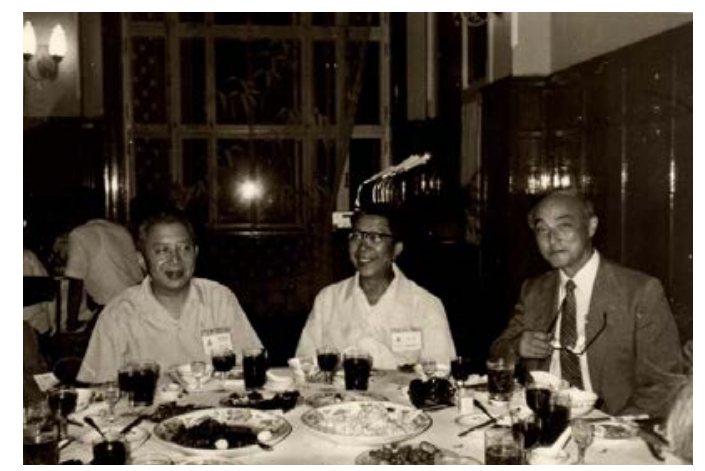

Fig. 24. Visit to China in 1982. From left: Min Enze (闵恩泽), Li Su (李苏 Secretary-General of Chinese Academy of Sciences), Tamaru Kenzi (田 丸謙二).

along with his daughter Hideko (秀子), the author's future wife. In Beijing they met with Lu Jiaxi (卢嘉锡), President of the Chinese Academy of Sciences and his daughter Lu Ziwei (卢紫莼) (Figs. 22-24). They had a Peking duck dinner at Quanjude. Lu Jiaxi joked that the reason he was overweight was that he had to host many visitors to Peking duck dinners. More seriously he stated that the future of China lay in investing in people; he also stated that it was important to send young people abroad for training [20].

In 1982, Tamaru Kenzi was invited to address the $50^{\text {th }}$ anniversary of the Chinese Chemical Society (Fig. 23). He gave his speech in Mandarin, and was told that it was easier to understand than some native Chinese speakers who had strong dialect accents. 


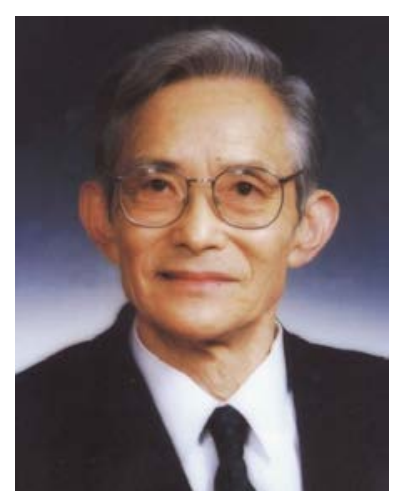

Fig. 25. Guo Xiexian (郭学贤, 1925-1998). Photo from Ref. [21].

What is remarkable is the strong friendship between Tamaru Kenzi and Guo Xiexian, which would last for decades until the passing of Guo Xiexian. The photos later in this section show their encounters in various places in the world.

Guo Xiexian (郭焂贤, Fig. 25), a native of Hangzhou, Zhejiang Province, was born in February 1925. In October 1946, he graduated from the Department of Applied Chemistry of Chongqing Binggong University. From 1947 to 1950, he served as Assistant Professor of the Department of Chemistry of Nanjing Central University. In 1950, he worked at the Dalian Institute of Chemical Physics, CAS. From 1958 to 1961, he served as Director of the Catalysis Research Laboratory of the Lanzhou Institute of Chemical Physics, CAS. In 1961, he returned to the DICP. In 1980, he was elected a member of the Chinese Academy of Sciences (an academician of the Chinese Academy of Sciences). He died on June 4, 1998 [21].

Guo Xiexian was engaged in research in the field of catalytic chemistry for decades and achieved fruitful results. He was responsible for the development of catalysts for the dehydrogenation and cyclization of toluene for the seven-carbon fraction of synthetic oil, and won the third prize of the Chinese Academy of Sciences. He carried out a project titled "Platinum Reforming and Multi-metal Reforming" which was awarded first prize in the Outstanding Achievements of the former Ministry of Petroleum. He was involved in the development of raw material purification catalysts (commercialized) and won the 1978 National Science Conference Award. He proposed a mechanism of alkane aromatic hydrocarbon semi-hydrogenation in basic research, the concept of surface "vacancy" adsorption and catalytic reaction, the three-membered ring mechanism of hydrocarbon isomerization and hydrogenolysis reaction, and a new concept of "translocation adsorption" and "cooperative mechanism" in the activation of hydrogen and carbon monoxide. He published more than 100 academic papers at home and abroad and trained more than 50 graduate students [21].

Guo Hefu and Guo Xiexian were Vice Directors under Director of Gu Yijian (顾以健) from April 1978 to April 1983 (Fig. 26). Guo Xiexian continued to serve as a Vice Director under Director of Lou Nanquan (楼南泉) from May 1983 to August 1986.

Guo Xiexian's daughter, Guo Yili, studied in the Chemistry Department of the University of California, Berkeley and ob-

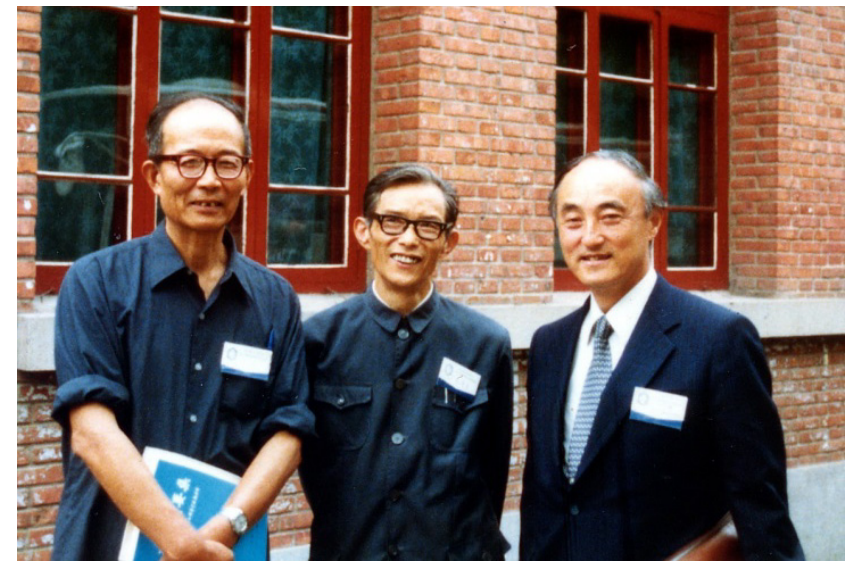

Fig. 26. Visit to Dalian in 1981. From left: Guo Hefu (郭和夫, the eldest son of Guo Moruo (郭沫若) and a Japanese wife), Guo Xiexian (郭熟贤), Tamaru Kenzi (田丸謙二). Photo: Tamaru family collection.

tained a Ph.D. degree. The Oyama family (Hideko and Ted) then lived nearby in the San Francisco Bay Area. Guo Xiexian befriended Oyama Shigeo Ted, son-in-law of Tamaru Kenzi. Guo Xiexian sent two students, Li Wei (李伟) and Zhang Weimin (张 卫民), to obtain doctorates in Oyama's laboratory, then at Clarkson University in Potsdam, New York; and they rose to high positions in the United States.

Guo Xiexian and his wife Liang Juan took Tamaru Kenzi to Xi'an and Dunhuang (敦煌). They rode on camels in Dunhuang In order to pay in Yuan in RMB, Tamaru Kenzi pretended to be Chinese. Guo Xiexian explained that he had a strong accent. See Figs. 27-30.

Tanabe Kozo (田部浩三) was a member of the first Japanese group that visited Beijing in 1975. In 1970 he had published his book "Solid Acids and Bases", which had a big impact. As a result many Chinese students went to his laboratory to study with him at Hokkaido University. Also in Hokkaido was Hattori Hideshi (服部英), who was a pillar of support in the Tanabe-Hattori laboratory. The following researchers came to the laboratory as doctoral students or visitors: Jin Tuo (1980 from Nankai University), Zhang Geng (1984 from Zhejiang University), Xu Boqing (徐柏庆, 1984 from Dalian University of Technology then at Tsinghua University), Xu Zheng (徐征, 1985

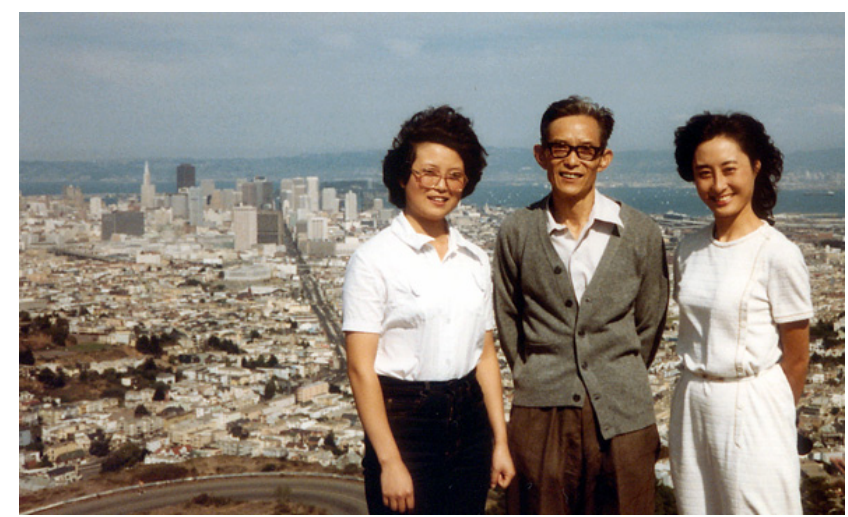

Fig. 27. In 1983 in San Francisco. From left: Daughter Guo Yili (郭一丽), Guo Xiexian (郭䝨贤), Hideko Tamaru Oyama (田丸秀子). 


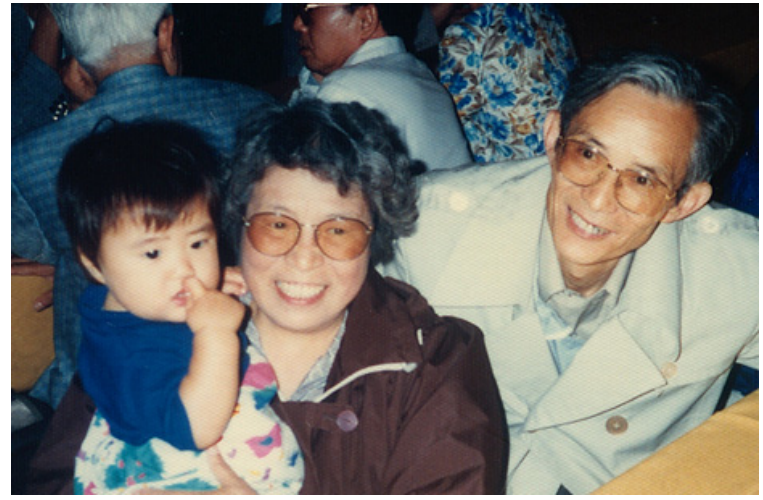

Fig. 28. Liang Juan (梁娟) and Guo Xiexian (郭哴贤) in 1988 in Calgary during the International Congress on Catalysis. The baby is Monika Oyama, daughter of the author. Photo: Tamaru family collection.

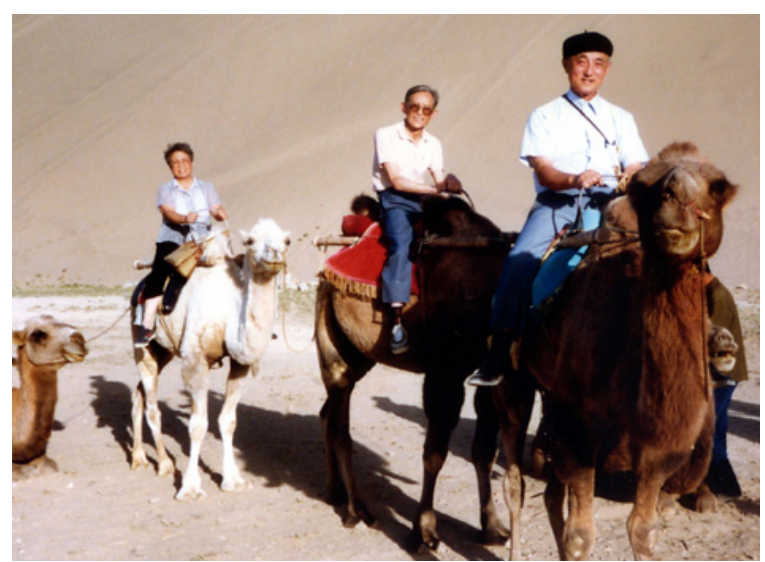

Fig. 29. In 1990 in Dunhuang (敦煌). From left: Liang Juan (梁娟), Guo Xiexian (郭卒贤), Tamaru Kenzi (田丸謙二). Photo: Tamaru family collection.

from Jilin University), Zheng Xiaoming (郑小明, 1985 from Hangzhou University, he was appointed as the Director of Hangzhou University in 1996). In 1988 Tanabe Kozo was recognized for his contribution to the Chinese Academic Society, and became Professor Emeritus of Jilin University [22].

Tanabe Kozo (田部浩三, Fig. 31) was born on May 7, 1926 in

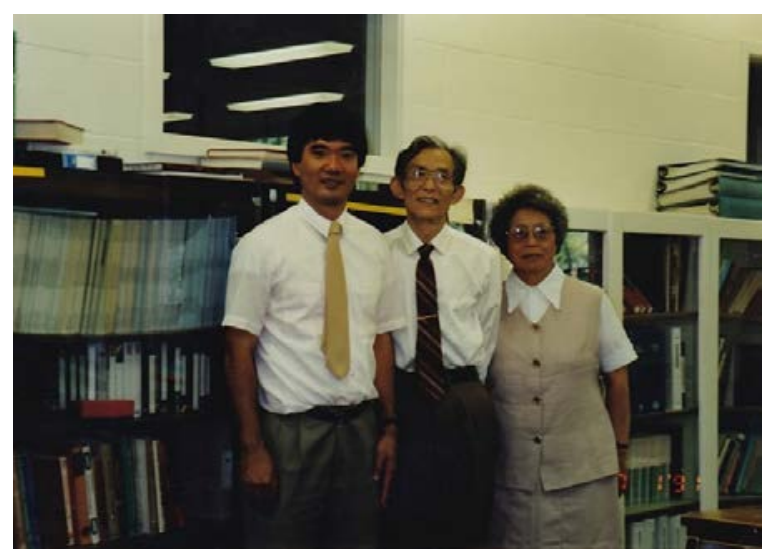

Fig. 30. Visiting Ted Oyama at Clarkson University in Potsdam in 1991, New York. From left: S. Ted Oyama, Guo Xiexian (郭菨贤), Liang Juan (梁娟). Photo: Oyama family collection.

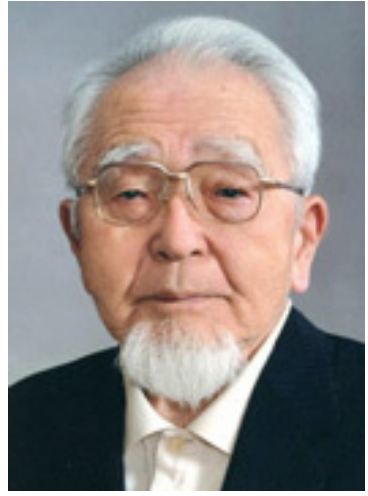

Fig. 31. Tanabe Kozo (田部浩三, 1926-2018). Photo from Ref. [23].

Takeda, Oita prefecture, Japan. He studied chemistry at Hokkaido University and graduated in 1951. He joined the Research Institute of Catalysis, Hokkaido University and received a Ph.D. in 1956. He remained on the faculty of the Research Institute of Catalysis and was promoted to Professor in 1960. In 1965, he moved to the Department of Chemistry at Hokkaido University, where he retired to become Professor Emeritus in 1990.

Professor Tanabe carried out early seminal work in acid-base catalysis by solids and discovered the essential role of acid-base pairs in conferring unique reactivity and selectivity by stabilizing intermediates through concerted interactions. He was a prolific and highly-cited author with more than 300 research publication and 10 books. Among these, the book entitled "Solid Acids and Bases" set the fundamental basis for the interpretation of the reactivity of oxides and mixed oxides in catalytic reactions and explained the benefits of an appropriate balance in strength between the acid and base active centers [23]. His achievements were recognized with many distinctions, among them several awards from the Chemical Society and the Catalysis Society of Japan and the Japan Institute of Petroleum. He was awarded the Medal with Purple Ribbon and the Order of the Sacred Treasure. Prof. Tanabe served as President of the Catalysis Society of Japan and as Vice President of the Chemical Society of Japan. His profound influence on the

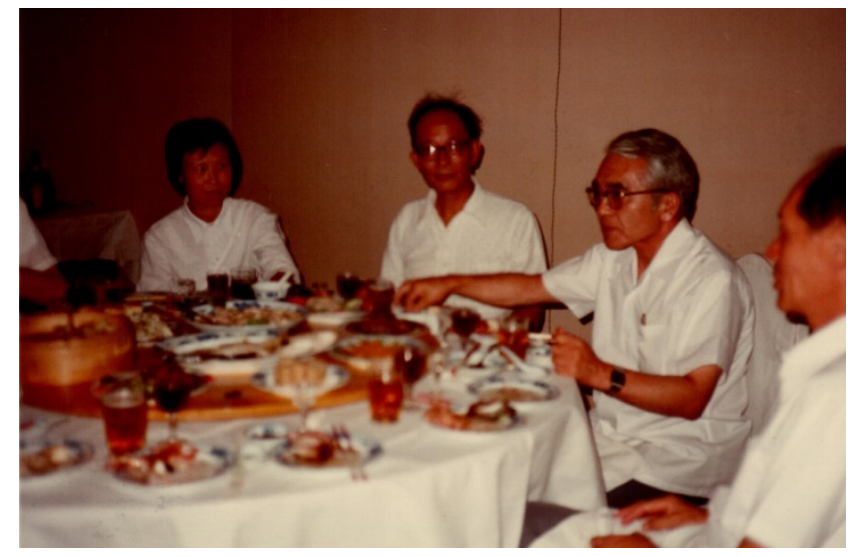

Fig. 32. In 1982. From left: Fang Lianqing, Guo Hefu (郭和夫), Tanabe Kozo (田部浩三), Lou Nanquan (楼南泉, Director of DICP in 1983-1986). Photo: Tamaru family collection. 


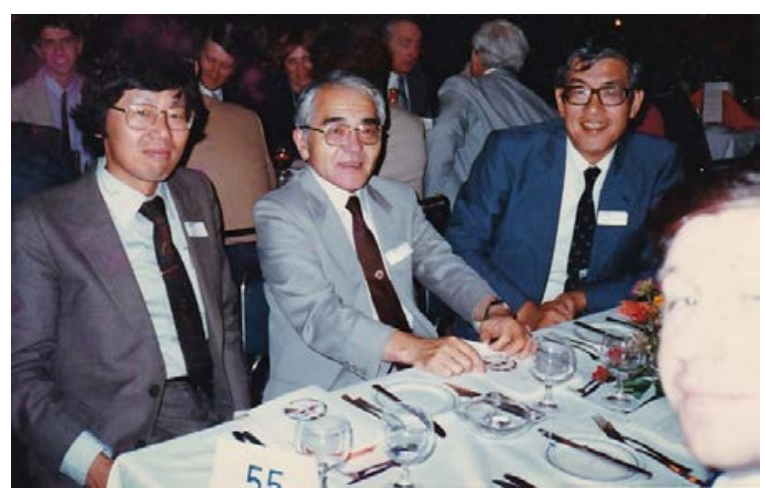

Fig. 33. At the 1984 International Congress on Catalysis, Calgary. From left: Aika Kenichi (秋鹿研一), Tanabe Kozo (田部浩三), Ohnishi Kohji ( 大西孝治). Photo: Tamaru family collection.

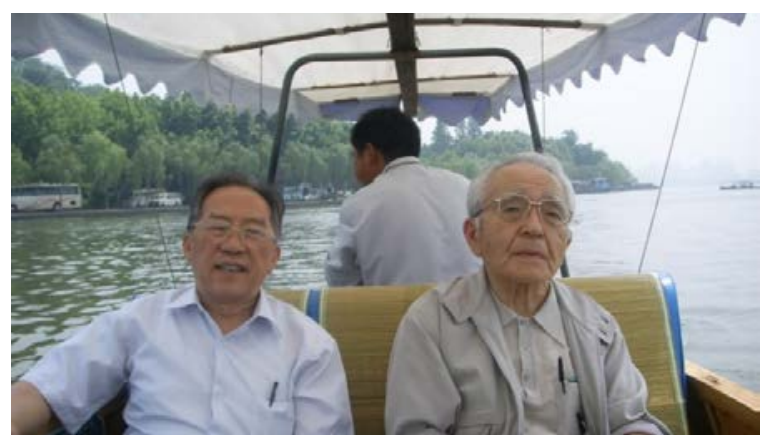

Fig. 34. At 2007 West Lake, Hangzhou, Zhejiang. From left: Xiong Guoxing (熊国兴), Tanabe Kozo (田部浩三). Photo: Courtesy of Xiong Guoxing.

field led to the creation of the "Tanabe Kozo Prize for Acid-Base Catalysis" in his honor; this prize is stewarded by the Scientific Advisory Board of the International Acid-Base Catalysis Symposium. Tanabe Kozo passed away on April 24, 2018 at the age of 91 [24]. See Figs. 32-34.

Prof. Tsai Khirui (蔡启瑞, Fig. 35) was born in Tongan (Xiamen, Fujian) in January 1914. In 1937 he graduated from Xiamen University and was appointed Assistant Professor. From 1947 to 1950, he studied at Ohio State University where he obtained his Ph.D. degree. In 1956, he returned to Xiamen University where he established the first Catalysis Program in China. He served as Vice-President of Xiamen University, and

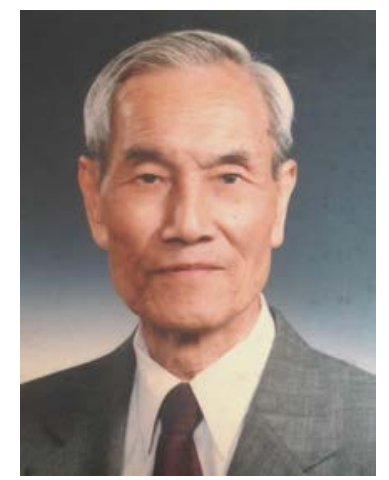

Fig. 35. Tsai Khirui (蔡启瑞, 1913-2016). Photo: Courtesy of Yuan Youzhu.

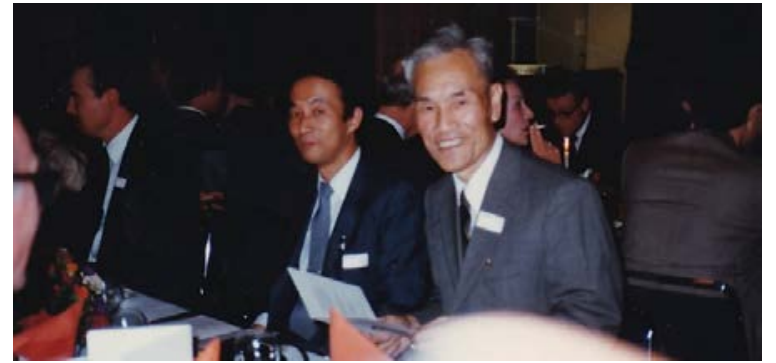

Fig. 36. At the 1984 International Congress on Catalysis, Berlin. From left: Naito Shuichi, Tsai Khirui (蔡启瑞).

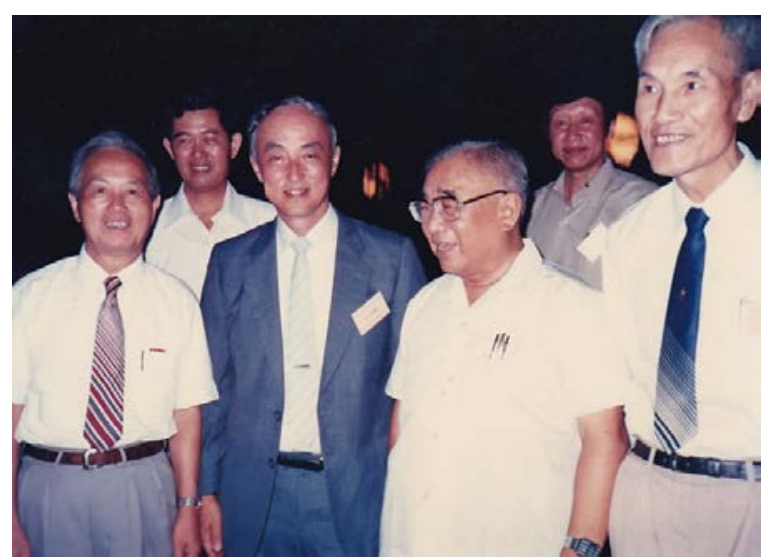

Fig. 37. At the 1987 China-Japan-USA Symposium at Xiamen University. From Left: Zhou Zhaomin (周昭民, electrochemist, to be Head of Chemistry Department, Xiamen University), Lin Zugeng (林祖庚, electrochemist, to be President of Xiamen University), Tamaru Kenzi (田丸謙 二), Lu Jiaxi (卢嘉锡, President of CAS, graduate from Xiamen University), Tsai Khirui (蔡启瑞). Photo: Tamaru family collection.

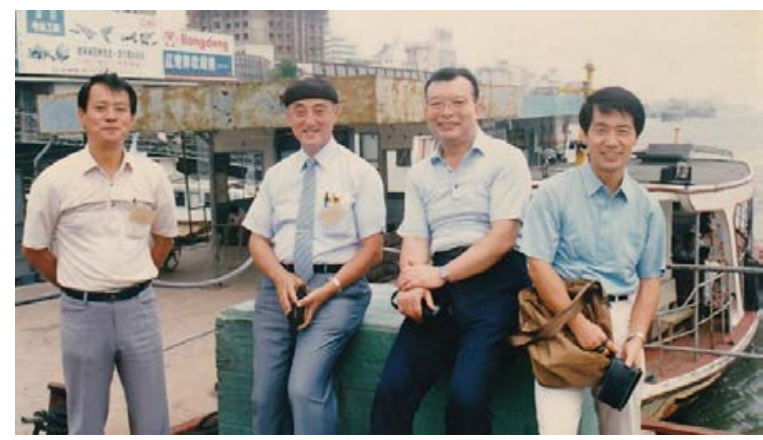

Fig. 38. Japanese participants in the China-Japan-USA Conference in Xiamen in 1987. From left: Misono Makoto (御園生誠), Tamaru Kenzi (田丸謙二), Yashima Tatsuaki (八嶋建明), Inoue Yasunobu (井上泰宣). Photo: Tamaru family collection.

was the Director of the State Key Laboratory of Physical Chemistry of Solid Surfaces. In 1980 he was elected as academician of the Chinese Academy of Sciences. His principal research interests were coordination catalysis, nitrogenase catalysis and metal-catalyzed ammonia synthesis, C1 chemistry, catalyst characterization methodology and structure-function relationships. He got three times the State Natural Science Award owing to his outstanding contribution to catalysis science. In 1999, he was awarded Ho Leung Ho Lee Prize for Science and Technology. He died on October 3, 2016 at the age of 104. See Figs. 36-38.

Prof. Tsai Khirui was a member of the Chinese delegation which attended the International Congress on Catalysis in To- 


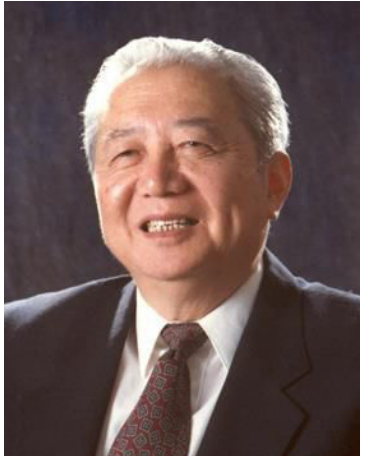

Fig. 39. Min Enze (闵恩泽, 1924-2016).

kyo in 1980. He was a major figure, and organized visits of foreigners to Xiamen, including this author.

Min Enze (闵恩泽, Fig. 39) was born on February 8, 1924 in Chengdu, Sichuan, China. In 1946, he graduated from the National Central University (Nanjing University), majoring in chemical engineering. In 1951, Min obtained a Ph.D. from Ohio State University in the United States. Between 1951 and 1955, he worked for the National Aluminate Corporation. In August

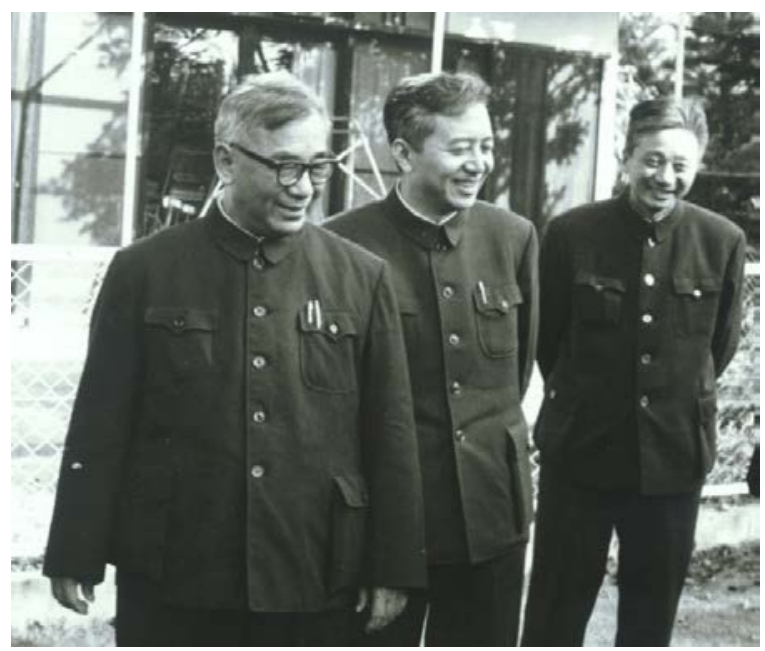

Fig. 40. Visit to Japan in 1977. From left: Lu Jiaxi (卢嘉锡), Min Enze (闵 恩泽), Unknown person.

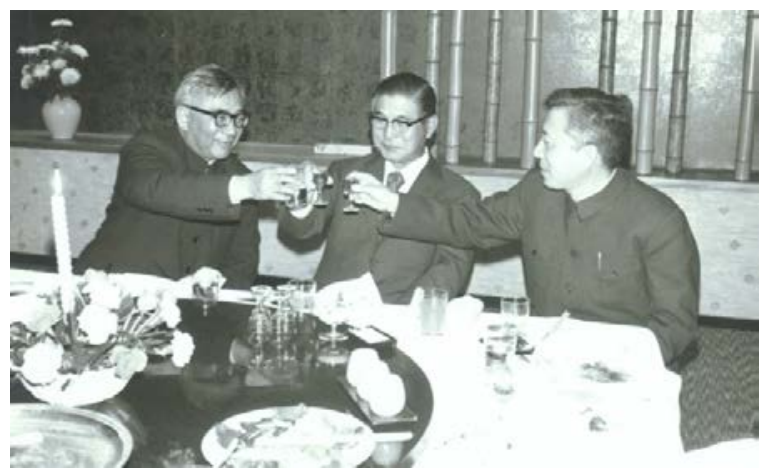

Fig. 41. Visit to Tokyo in 1977. From left: Lu Jiaxi (卢嘉锡), Mizushina Takuro (水科篤郎, Professor of Engineering and Director of Energy Research at Kyoto University), Min Enze (闵恩泽). Photo: Tamaru family collection.

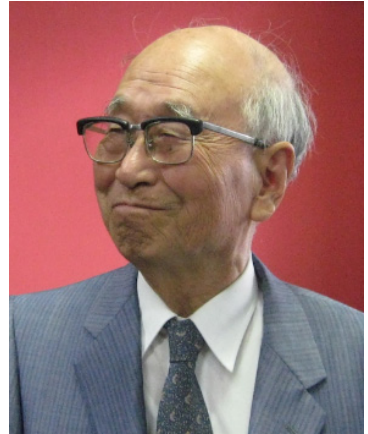

Fig. 42. Ozaki Atsumu (尾崎萃, 1920-2013). Photo: Courtesy of Aika Kenichi (秋鹿研一).

1955, he returned to China and was assigned work at the Beijing Institute of Oil Refining (now Research Institute of Petroleum Processing of the China Petroleum and Chemical Corporation). Min was elected an academician of the CAS in 1980, a member of the Third World Academy of Sciences (TWAS) in 1993, and an academician of the Chinese Academy of Engineering in 1994. He served as the Chairman of the academic committee of the Research Institute of Petroleum Processing of the China Petroleum and Chemical Corporation (Sinopec). Min received the Highest Science and Technology Award in 2007, the most prestigious scientific prize awarded in China. Min died on 7 March 2016 at the age of 92 in Beijing [25]. Aside from his many technological achievements Min left behind many capable students. See Figs. 40, 41, and 65.

Ozaki Atsumu (尾崎萃, Fig. 42) was born in Aichi prefecture on June 16, 1920. In 1943, he graduated from the Fuel Engineering Department of the Tokyo Institute of Technology, and then advanced to the graduate school, which he completed the next year. In 1945 he became Assistant Professor in the same Department. From 1957 to 1959, he studied in the laboratory of Sir Hugh Taylor at Princeton University. In 1962 he was promoted to Full Professor. From 1970 to 1973, he was co-Director of the Institute for Resource Chemistry. He retired in 1981.

He conducted pioneering research in the field of catalytic chemistry, and trained many researchers, including Aika Kenichi. The focus of his research was the elucidation of physical reaction mechanisms and the design of engineering catalysts. In particular, he invented a new ruthenium catalyst that could replace the Haber-Bosch iron catalyst with 80 years of history (July 1980, Patent No. 1005414). The catalyst was commercialized in Canada in 1992 in an improved form. He also did groundbreaking work in the identification of adsorbed species by isotope exchange and kinetic methods. In 1980 he won the Japan Chemical Society Award and in 1981 the Tokyo Metropolitan Government Science and Technology Achievement Award. He died on April 20, 2013.

The early period of exchanges between China and Japan roughly from 1975 to 1990 saw the involvement of the scientists mentioned above. The list is not comprehensive and others not mentioned in detail were involved such as Yoneda Yukio (米田幸夫), Horiuti Toshiro (掘内寿郎), Onishi Koji (大 西孝治), Hattori Hideshi (服部英), Ono Yoshio (小野加夫), 


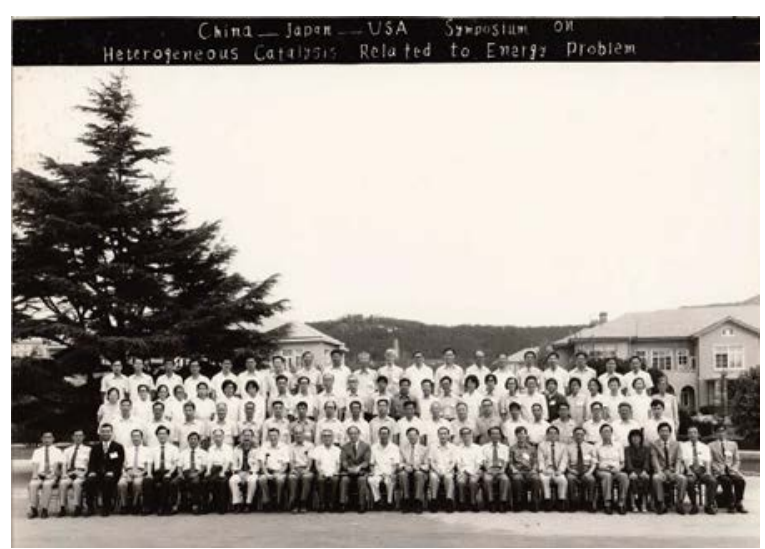

Fig. 43. First China-Japan-USA Symposium on Heterogeneous Catalysis organized by Guo Xiexian held on September 1-2, 1982 at the Dalian Bangchui Island Hotel. Photo: Courtesy of Iwasawa Yasuhiro.

Jiang Bingnan (姜炳南, DICP), Zhang Hongbin (张鸿斌, Xiamen), Yin Yuangen (尹元根, Lanzhou), Xie Xiaofan (谢䈗帆, Changchun and Deng Jingfa (邓景发, Shanghai). Visits went both ways, from China to Japan and Japan to China.

An important aspect of this early period saw the beginning of participation of Chinese scientists in international conferences. In 1980, the $7^{\text {th }}$ International Congress on Catalysis was held in Tokyo. As described by Xin and Li, in past congresses there were almost no Chinese attendees, but for this meeting the government sent a delegation comprising Min Enze (闵恩 泽), Tsai Khirui (蔡启瑞), Guo Xiexian (郭䃞贤), Lin Liwu (林励 吾), and Yin Yuangen (尹元根) [13].

A very important step was the organization of conferences in China. On September 1-2, 1982, Guo Xiexian organized the first China-Japan-USA Symposium on Catalysis, which was held in Dalian (Fig. 43). His friend, Tamaru Kenzi, helped in enlisting top scientists from America, and among those who came were Alex Bell, Gary Haller, John Peri, Al Vannice, and Margaret Wilson. This was a successful meeting with over 90 attendees.

\subsection{Later exchanges (1990-present)}

After the opening of China to scientific exchange in catalysis in the period 1975-1990, the number of interactions grew considerably. China sent hundreds if not thousands of students

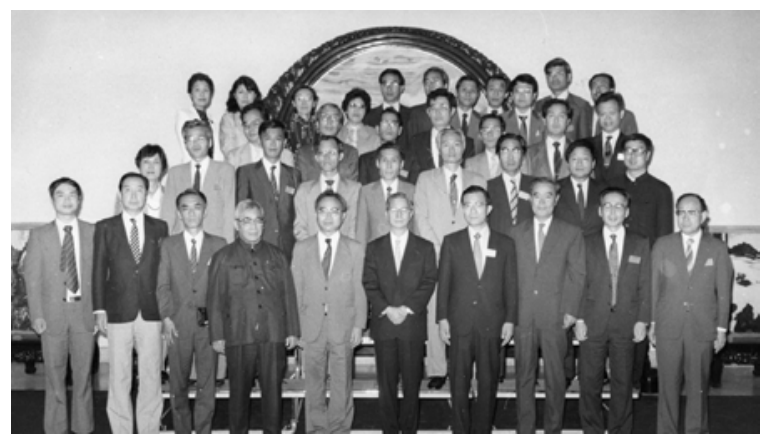

Fig. 44. First China-Japan Symposium on Coal and C1 Chemistry organized by Bao Hanchen and Tamai Yasukatsu in Taiyuan on September 1985. Photo: Courtesy of Li Xiaohong.

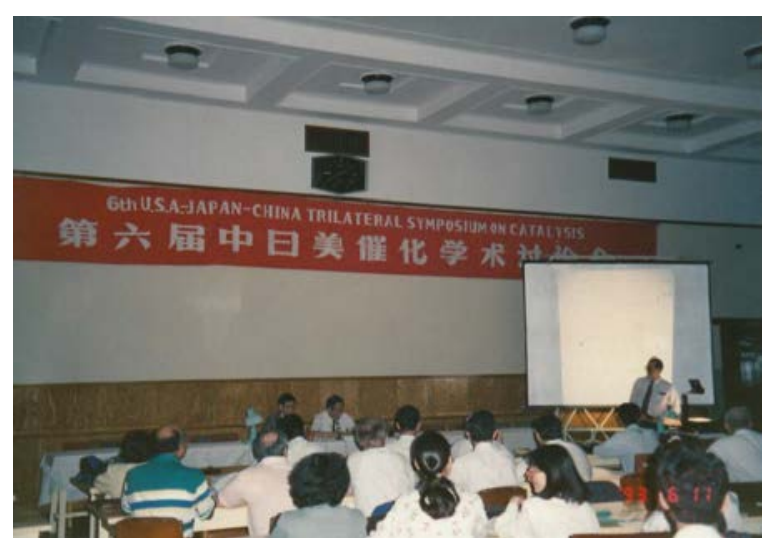

Fig. 45. $6^{\text {th }}$ China-Japan-USA Symposium on Catalysis, June 11-13, 1993 Beijing. Photo: Courtesy of Iwasawa Yasuhiro.

abroad for study and training. China participated in major international conferences abroad and actively organized major meetings at home. As documented by Xin and Li [13] and Yuan [26], the first China-Japan-USA Symposium on Heterogeneous Catalysis was followed by others in Berkeley (July 1985), Xiamen (August 1987), and Sapporo (July, 1989). Eventually, this conference series was expanded to become the Asian-Pacific Congress on Catalysis (APCAT), with a Standing Secretariat set in Dalian and Professor Xiao Fengshou (肖丰收) as the Secretary General. This step was decided during the $12^{\text {th }}$ International Congress on Catalysis (ICC) in Granada, Spain, 2000. Thereafter, APCAT meetings were held successfully 13 times, first in South Korea, then in Australia, followed by meetings in Japan, China, Singapore, Taipei, and India. The APCAT, together with the North American Catalysis Conference and the European Catalysis Conference, has become one of the three large regional conferences on catalysis, second only to the quadrennial ICC (Fig. 44-48).

As also reported by Xin and Li [13] many other conferences were begun or held in China. Among these were the Sino-Japanese Conference on Precious Metal Catalysis held in Dalian on June 10-13, 1987, the $4^{\text {th }}$ International Conference on Spillover held in Dalian on September 15-18, 1997 (the first

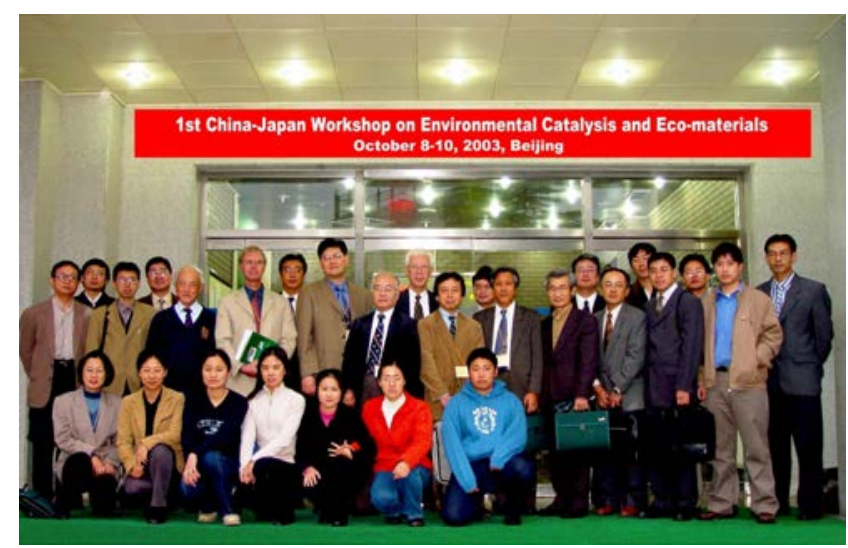

Fig. 46. First China-Japan Workshop on Environmental Catalysis and Eco-Materials held on October, 8-10, 2003 in Beijing. Center: He Hong and Tanaka Kenichi. Photo: Courtesy of He Hong. The $8^{\text {th }}$ Workshop was held on December, 5-6, 2017 in Tsukuba, Japan. 


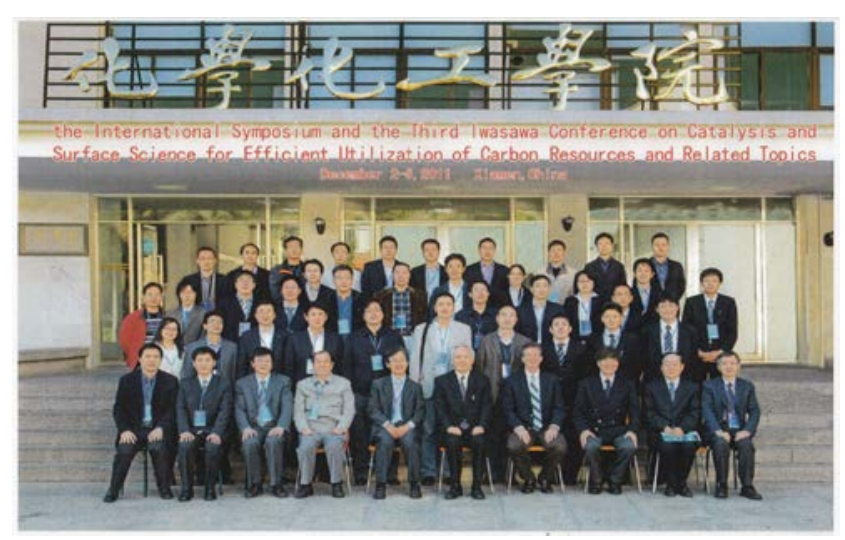

Fig. 47. The International Symposium and the Third Iwasawa Conference on Catalysis and Surface Science for Efficient Utilization of Carbon Resources and Related Topics, Xiamen, December, 2-5, 2011. Photo: Courtesy of Iwasawa Yasuhiro.

international conference hosted by Chinese catalytic community, which attracted scientists from 15 countries), the $7^{\text {th }}$ International Conference on Inorganic Membranes held in Dalian on June 23-26, 2002, the $5^{\text {th }}$ International Conference on Catalysis in Membrane Reactor held in Dalian on June 26-28, 2002, the $3^{\text {rd }}$ World Petroleum Congress hosted by Sinopec, and the Sino-Japanese C1 Chemistry Conference. A major series of conferences were the China-Japan workshops on Environmental Catalysis and Eco-materials started by He Hong in 2003 and the long running China-Japan Symposium on Coal and C1 Chemistry started by Bao Hanchen and Tamai Yasukatsu in Taiyuan on September, 1985 and continuing to its $13^{\text {th }}$ edition in Dunhuang in September 2015 [27]. There were also a number of special symposia held in China in honor of Iwasawa Yasuhiro (in Xiamen), Fujimoto Kaoru (in Liaoning 2017) and Tanaka Kenichi (in Xiamen in 2011). These showed the increasing influence of China was having on the world, whose apex would be the hosting of the $16^{\text {th }}$ International Congress on Catalysis in Beijing in 2016, with Li Can presiding as the President of the International Association of Catalysis Societies.

It is not possible to document the extensive interactions that occurred between China and Japan in catalysis after 1990. In the following will be presented short summaries of the professional lives of professors of universities, following roughly their

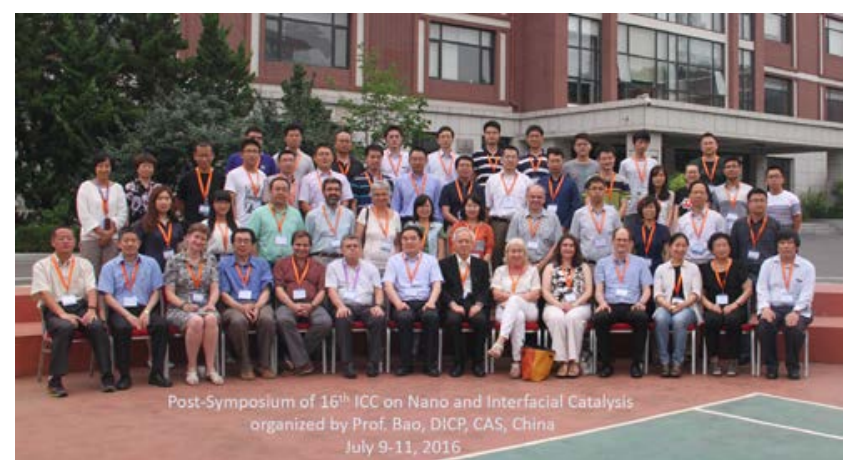

Fig. 48. Post-Symposium of the $16^{\text {th }}$ International Congress on Catalysis on Nano and Interfacial Catalysis (Bao Xinhe, organizer) DICP, CAS, Dalian China, July 9-11, 2016. Photo: Courtesy of Iwasawa Yasuhiro.

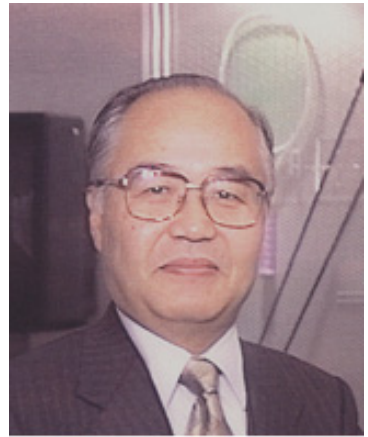

Fig. 49. Tanaka Kenichi (田中虔一 1937-2018). Photo: Courtesy of He Hong.

year of birth. The individuals can be categorized as Japanese who contributed to China, Chinese professors especially from DICP who contributed to the international community including Japan, Chinese professors who were educated in Japan, and finally Chinese professors who teach in Japan. The author acknowledges that the listing is far from complete, especially missing a number of Professors like Fujimoto Kaoru (藤元薰), Morooka Yoshihiko (諸岡良彦), Misono Makoto (御園生誠), Ohno Yoshio (小野嘉夫), Mochida Isao (持田勲), Xu Yide (徐奕 德), and Bai Chunli.

\subsubsection{Japanese professors who contributed to China}

Tanaka Kenichi (田中虔一, Fig. 49) was born on May 8, 1937 in Nagano Prefecture, Japan. In 1969 he got his Ph.D. at Yokohama National University with Tamaru Kenzi. From 1967 to 1972 he was a Research Associate at the Tokyo Institute of Technology and from 1972 to 1984 he was Associate Professor at Hokkaido University. From 1985 to 1987 he was Associate Professor at the University of Tokyo, Institute of Solid State Physics, and from 1988 to 1998, was Full Professor in the same Institute. From 1998 to 1999, he was Guest Professor at Xiamen University and Waseda University; from 2002 to 2008, he was Professor at Saitama University, and from 2002 to 2018 he was Guest Professor at the Research Center for Eco-Environmental Sciences, Chinese Academy of Sciences, China. His research concentrated on surface science, nano-materials on surfaces, catalysis, and reaction mechanisms. He received the following recognitions: in 1985 the 2nd Academy Award of the Chemical Society of Japan, in 1995 the Award from the Catalysis Society of Japan, and in 1997 the $1^{\text {st }}$ Award of the Surface Science Society of Japan.

Aika Kenichi (秋鹿研一, Fig. 50) was born on March 17, 1942 at Numazu-city, Shizuoka prefecture. He obtained his doctorate in 1969 from the Department of Chemical Engineering of the Tokyo Institute of Technology and became an Assistant Professor in the laboratory of Ozaki Atsumu in the same department. In 1974, he was a researcher at Princeton University and in 1975 at Texas A\&M University with Jack Lunsford. In 1992, he advanced to Professor and remained in that position until 2004. From 2005 to 2009, he served as Executive Director of the Science and Technology Promotion Organization, and from 2007 to 2012 he was Director of the Tokyo Setagaya Learning Center of Tokyo University. He has been 


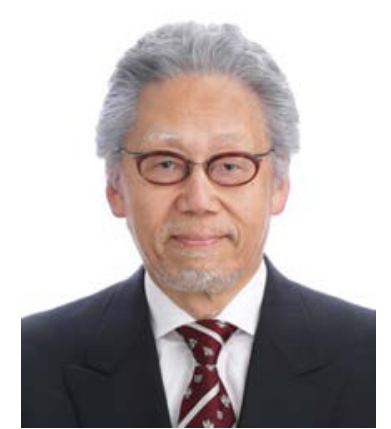

Fig. 50. Aika Kenichi (秋鹿研一, 1942-).

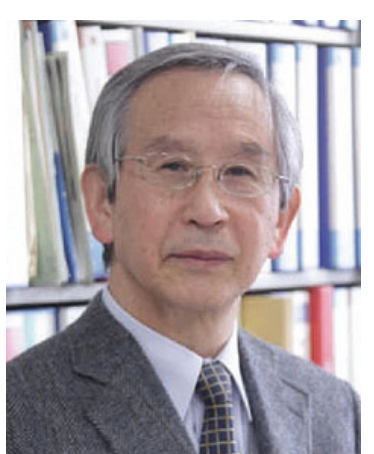

Fig. 52. Masatake Haruta (春田正毅, 1947-). recognized with the RITE Excellent Research Award in 1991 for work on "Ethylene Production from Methane and $\mathrm{CO}_{2}$ ", by a Japan Catalysts Society Award in 1998 for research on the "Study on Ruthenium Catalyst for Ammonia Synthesis", and by a Ministry of Education, Culture, Sports, Science and Technology Prize in 2003 for "Research on high-performance ruthenium catalyst for ammonia synthesis".

Iwasawa Yasuhiro (岩澤康裕, Fig. 51) was born on March 13, 1946 in Saitama Prefecture, Japan. In 1968 he obtained his B.S. degree and in 1973 his Ph.D. from the University of Tokyo, working in the laboratory of Tamaru Kenzi. From 1972 to 1984, he was at Yokohama National University where he rose from Research Associate to Associate Professor. From 1984 to 2009, he was at the University of Tokyo where he rose from Associate Professor to Full Professor. From 2009 to 2011, he was Professor at the University of Electro-Communicartions. Yasuhiro Iwasawa is an expert on catalysis and surface science, particularly on catalyst characterization by advanced XAFS and related X-ray techniques. His first visit to Dalian was in 1982. At that time, he was one of the delegates of younger Professors from Japan to attend the 1 ${ }^{\text {st }}$ China-Japan-USA Symposium on Heterogeneous Catalysis Related to Energy, organized by DICP. This meeting was a historic and pioneering meeting in the developments of scientific research and international exchange in catalytic discipline in China. After that, Prof. Iwasawa was invited to visit DICP many times. For example, he was invited to work as an international expert for the International On-site Review Meeting on Fundamental Researches of DICP in 2005 and to be as a keynote and plenary lecturer of international symposiums/meetings organized by DICP.

Masatake Haruta (春田正毅, Fig. 52) was born in 1947. In

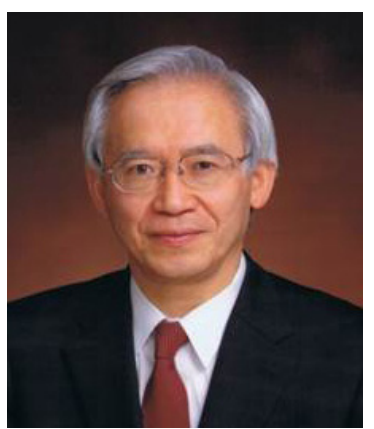

Fig. 51. Iwasawa Yasuhiro (岩澤康裕 1946-).
1970, he received a B.S. degree in Industrial Chemistry from the Nagoya Institute of Technology and in 1975 a Ph.D.degree in Electrochemistry from the Graduate School of Engineering, Kyoto University. In the same year he started his career at the Osaka National Research Institute (ONRI), where he was involved in a project on the catalytic combustion of hydrogen with base metal oxides. From 1981 to 1982, he stayed at the Universite Catholique de Louvain with Bernard Delmon. In 1990, he was promoted to the Head of the Catalysis Section, ONRI, and in 1999 to Director of the Department of Energy and the Environment. In 2001 he moved to Tsukuba to work as Director of the Research Institute for Green Technology, National Institute of Advanced Industrial Science \& Technology (AIST). From 2005 to 2018, he was a Professor at the Tokyo Metropolitan University (TMU). In 2012, he was invited as Visiting Professor for Senior International Scientists of the Chinese Academy of Sciences and became Director of the Gold Catalysis Research Center of the Dalian Institute of Chemical Physics (DICP). From 2013 to 2018, he was also Director of the Research Center for Gold Chemistry of TMU.

In 1989, Prof. Haruta reported that gold in nano particle form became a very active catalyst for $\mathrm{CO}$ oxidation, opening a new field in catalysis. He is known in the world as "the father of gold catalysis". The contribution is evidenced by awards and honors such as 15th Osaka Science Prize in 1977, the Chemical Society of Japan Award in 2010, and the Thomson Reuters : Citation Laureate in Chemistry (Nobel Prize) in 2012 [28].

Asakura Kiyotaka (朝倉清高, Fig. 53) was born on June 12, 1958 in Fukuoka, Japan. In September 1987 he obtained his Ph.D. from the University of Tokyo. From 1984 to 1992 he rose

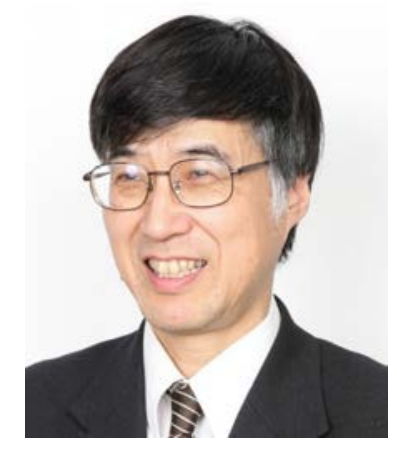

Fig. 53. Asakura Kiyotaka (朝倉清高). 


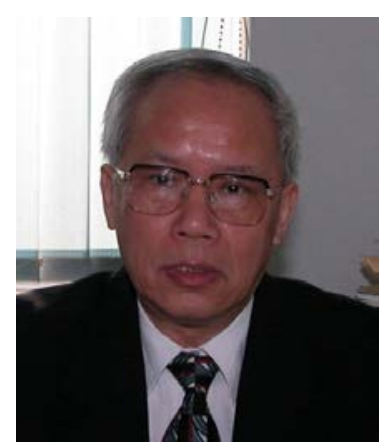

Fig. 54. Xu Yide (徐奕德) 1940-).

from Research Associate to Lecturer at the University of Tokyo. From March 1993 to April 1994 he worked with Gerhard Ertl at the Fritz Haber Institute in Dahlem, Berlin. In May 1995 he returned to the University of Tokyo as Associate Professor at the Research Center of Spectrochemistry. In April 1994, he became Full Professor at the Catalysis Research Center of Hokkaido University and from 2015 to 2018 he served as Director of the Institute of Catalysis of Hokkaido University.

\subsubsection{Chinese professors who contributed to the international community}

Xu Yide (徐奕德) was born on January 14, 1940 in Shanghai. He was a Visiting Scholar and Professor in the UK, France, Spain, Japan and the USA. He was Director of the State Key Laboratory of Catalysis in DICP from 1992 to 1997. In 2000, he won the Excellent Paper Prize of the National Natural Science Foundation of China. In 2003, he was the first awardee of the $2^{\text {nd }}$ Prize of Natural Science in Liaoning Province. In 2005, he was the First Awardee of the $2^{\text {nd }}$ Prize of the National Natural Science of China. Research in his laboratory led to the first methane aromatization catalyst (Mo/ZSM-5), which attracted world-wide attention. He collaborated with Ichikawa Masaru in Hokkaido University. See Figs. 54-57.

One of the students of Xu Yide was Shu Yuying (舒玉瑛). In 2000, she got a Ph.D. in physical chemistry and catalysis from

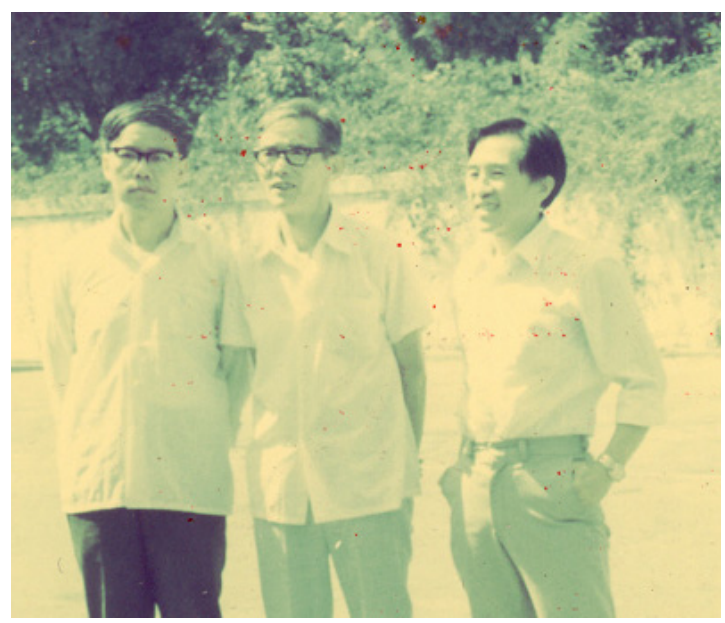

Fig. 55. Meeting to establish the first Key Laboratory in Catalysis, Dalian, 1984. From left: Xu Yide, Guo Xiexian, Xiong Guoxing. Photo: Courtesy of Xiong Guoxing.

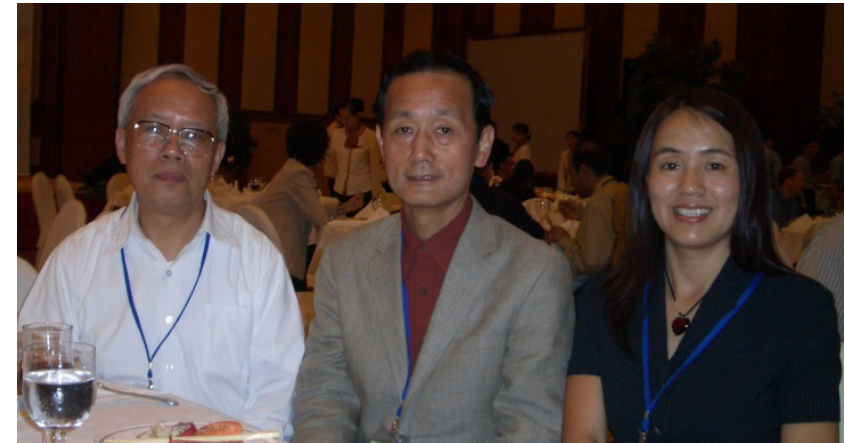

Fig. 56. $7^{\text {th }}$ Natural Gas Symposium, Dalian, June 6-10, 2004. From left: Xu Yide, Ichikawa Masaru, Shu Yuying.

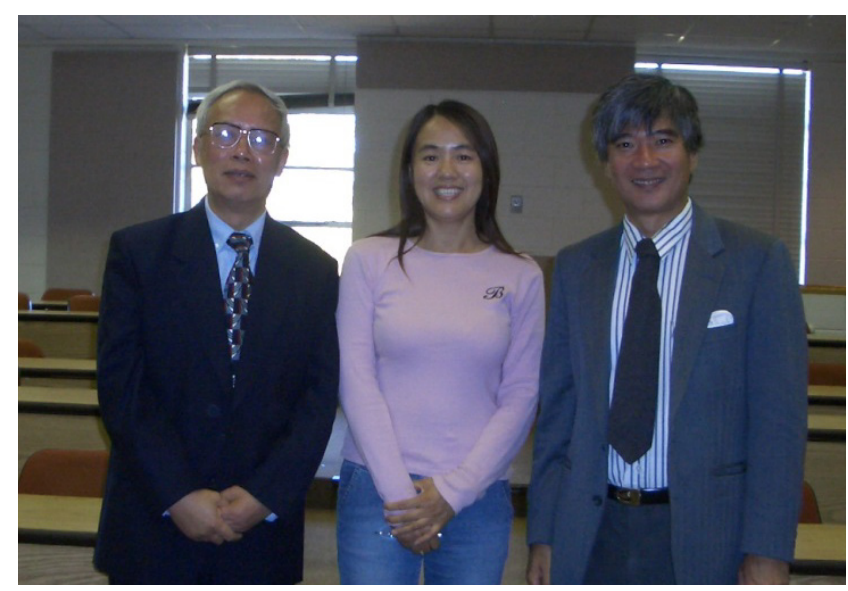

Fig. 57. Visit of Xu Yide to Virginia Tech in 2005. From left: Xu Yide, Shu Yuying, Ted Oyama. Photo: Courtesy of Shu Yuying.

DICP. Then from 2001 to 2002, she worked with Ichikawa Masaru in Hokkaido University and from 2002 to 2005 with Ted Oyama at Virginia Tech, Then from July 2005 to December, 2006 she was an Associate Professor at the State Key Laboratory of Catalysis in DICP. From December, 2006 to the present she has been working at W.R. Grace in Columbia, Maryland, USA, where she rose from Research \& Development Engineer to Senior Engineer and Principal Engineer.

Bao Xinhe (包信和, Fig. 58) was born on August 26, 1959 in Yangzhong, Jiangsu. In 1987, he received his Ph.D. in Physical Chemistry from Fudan University and then worked as a Fellow

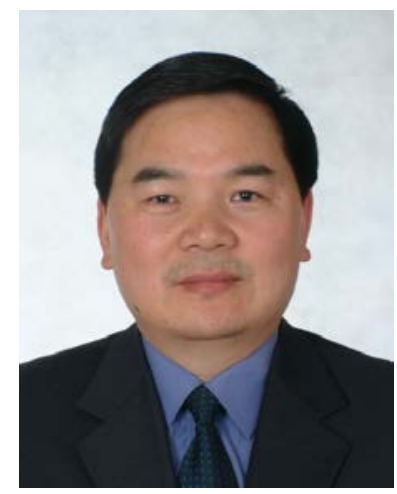

Fig. 58. Bao Xinhe (包信和, 1959-). 


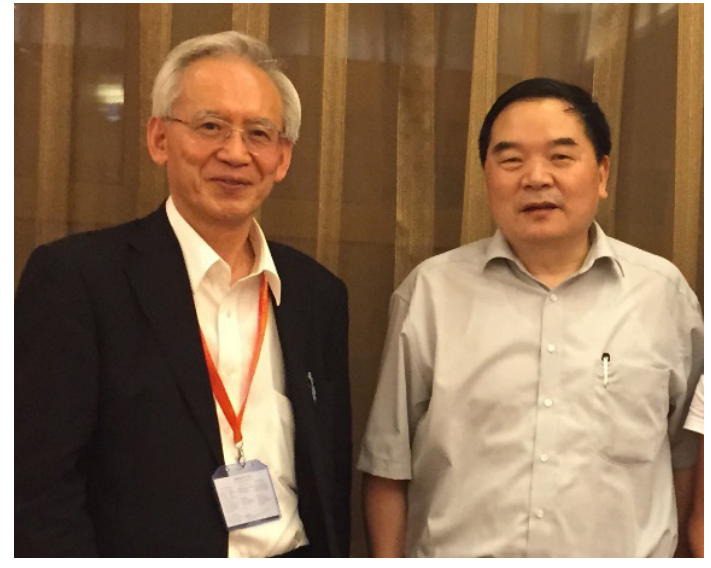

Fig. 59. Post-symposium of the 16th International Congress on Catalysis: Nano and Interfacial Catalysis in Dalian on July 9th, 2016. From left: Bao Xinhe, Iwasawa Yasuhiro. Photo: Courtesy of Bao Xinhe.

of the Alexander von Humboldt in the Fritz Haber Institute of the Max-Planck Society in Berlin, Germany. In 1995, he became a full Professor at the Dalian Institute of Chemical Physics (DICP, CAS) and later group leader of the Nano \& Interface Catalysis group at the State Key Laboratory of Catalysis. From 2000 to 2007, he held the position of Director of the Institute, then from 2009 to 2014 he was President of the Shenyang Branch of the Chinese Academy of Sciences. From 2015 to 2017, he was the Executive Vice President of Fudan University and in 2017 he was appointed President of the University of Science and Technology of China.

Bao Xinhe is member of the Chinese Academy of Sciences and Honorary Fellow of the Royal Society of Chemistry (UK). He is currently the Vice President of the Chemistry Society of China and the President of the Chinese Society of Catalysis. Bao is Editor-in-chief of the Journal of Energy Chemistry. Bao Xinhe's research focuses mainly on the fundamental understanding of catalysis, and its application to the development of new catalysts and catalytic processes related to energy conversion, in particular clean coal and natural gas utilization. He has published more than 700 scientific papers and one book (Elsevier) and filed 160 patents. In 2005 he was awarded the National Science Award (second Class, 2005), in 2012 the Ho Leung Ho Lee Foundation for scientific and Technological Progress Award in Chemistry, in 2015 the Award in Basic Science from the Zhou Guang Zhao Foudation, in 2015 also the Outstanding Science and Technology Acheivement Prize of the Chinese Academy of Sciences, in 2016 the Outstanding Achievement Award of International Natural Gas Conversion, in 2017 the Alwin Mittasch Prize, and in 2018 the Tan Kah Kee Science Award.

Li Can (李灿, Fig. 60) was born on January 13, 1960 in Jinchang, Gansu. In 1985 he obtained his M.S and in 1988 his Ph.D. in Physical Chemistry/Catalysis Chemistry from DICP. From 1989 to 1993 he advanced from Assistant Professor to Full Professor at DICP. Prof. Li has been working on both fundamental and applied research in catalysis and making efforts to reveal the essential relationship between catalytic performance and catalyst structure Li Can has over 700

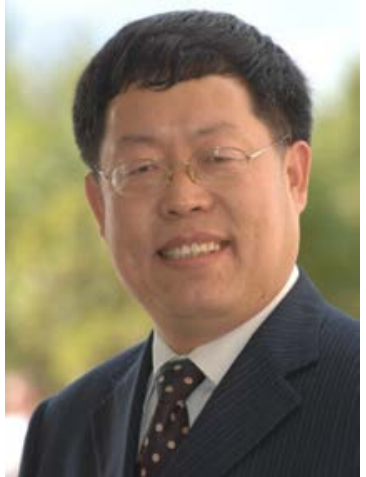

Fig. 60. Li Can (李灿, 1960-).

publications, 80 awarded patents and over 100 plenary and keynote lectures at international conferences.

Since $2011 \mathrm{Li}$ Can has been the Director of the Dalian National Laboratory for Clean Energy and between 1998 and 2015 was the Director of the State Key Laboratory. From 2005 to 2012, he served as Chairman of the Catalysis Society of China and from 2008 to 2012, he was the President of International Association of Catalysis Societies. In 2003, Li Can was elected a Member of the Chinese Academy of Science and in 2008 was made a Foreign Member of Academia Europea and a Fellow of the Royal Society of Chemistry. His honors include in 1993 the Prize of the Japan-China Sci. Tech. Association, in 1994 the Japan Industry Newspaper Prize, in 1998 the Noguchi Prize of the Japan Petroleum Institute, in 2000 the Progress Prize of the Japan Institute of Energy, and in 2006 the Prize of the JSPS (Japan Society for the Promotion of Science). In 2014, he was awarded the National Catalysis Achievement Award of China for his outstanding contribution to catalysis and in 2017 the Award of the Japan Institute of Energy. In 2017, he was elected as member of the Science Council of Japan. Very recently, Li Can was awarded the Japanese Photochemistry Association Elsevier Lectureship Award. Zhang Tao (张涛, Fig. 62) was born on July 8, 1963 in Ankang, Shaanxi. In 1989, he received his Ph.D. from DICP. After one year at the University of Birmingham as a

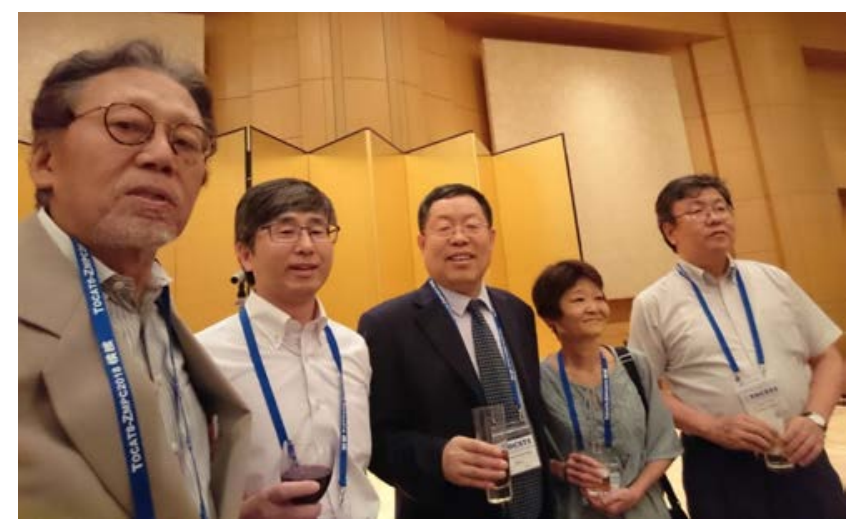

Fig. 61. Tokyo Conference on Catalysis (TOCAT) 2018 in Yokohama, Japan Photo: Courtesy of Aika Kenichi (秋鹿研一). From left: Aika Kenichi (秋鹿研一), Kubo Akihiko, Li Can, Nomura Junko, Sakata Yoshihisa. 


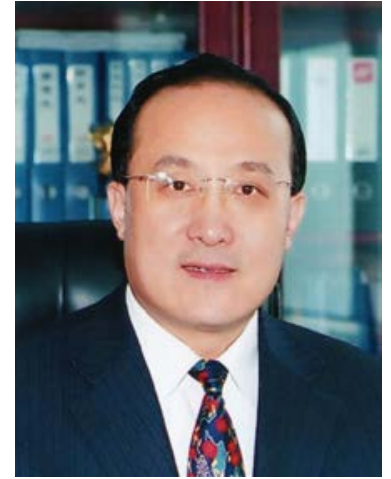

Fig. 62. Zhang Tao (张涛, 1963-).

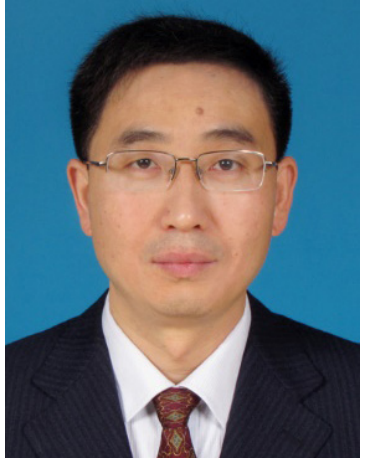

Fig. 64. Liu Haichao (刘海超, 1968-). post-doctoral fellow, he joined DICP again in 1990 where he was promoted to a full Professor in 1995. From 2007-2016, he was the Director of DICP and is now the Vice President of the Chinese Academy of Science (CAS). His research interests are mainly focused on the catalytic conversion of biomass and nano-catalysis. He is the author or co-author of more than 360 peer-reviewed scientific publications and 110 patents. He has been Editor-in-Chief of the Chinese Journal of Catalysis since 2014.

Professor Tao Zhang has won many important awards, such as the National Invention Prize (three times), the Distinguished Award of the CAS, Excellent Scientist Award of the Chinese Catalysis Society, the Ho Leung Ho Lee Prize for Science and Technology, and the Science China Materials Innovation Award. In 2012, he was elected Fellow of the Royal Society of Chemistry, and in 2013 a member of the Chinese Academy of Sciences.

Liu Zhongmin (刘中民, Fig. 63) was born in Henan Province on Sept 24, 1964. He received his B.S. degree in Physical Chemistry from Zhengzhou University in 1983 and his Ph.D. in Physical Chemistry from Dalian Institute of Chemical Physics in 1990. He has been the Director of Dalian Institute of Chemical Physics, CAS since 2017. In 2006, Prof. Liu and his colleagues successfully demonstrated industrial methanol-to-olefins (DMTO) technology. Based on this, the world's first commercial MTO unit was built by the Shenhua group, which is a milestone in the field of coal to chemicals. Besides DMTO, Prof. Liu has also developed many other new catalysts and catalytic processes, such as methanol to ethanol, propylene to isopropanol

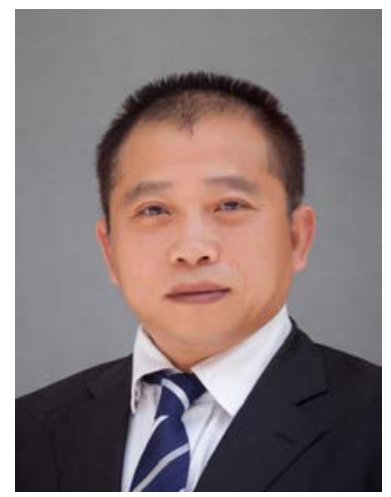

Fig. 63. Liu Zhongmin (刘中民, 1964-). Photo from Ref. [29]. and methanol to dimethyl ether. Recently, the world's first Coal-to-Ethanol (methanol to ethanol) demonstration plant (100 KTA ethanol) was commissioned.

By the end of October 2018, Zhongmin Liu educated more than 40 graduate students with M.S. and Ph.D degrees, published more than 300 papers and 1 academic monograph, and held 351 authorized effective patents, including 198 China patents and 153 foreign patents. Prof. Liu is in the editorial board of "Journal of Chinese Catalysis", "Journal of Energy Chemistry", "Progress in Chemical Industry", and is the dean of the College of Energy, Chinese Academy of Sciences, the Vice Chairman of the Chinese Petroleum Society, and a standing member of the Chemical Industry and Engineering Society of China. In 2015 he received the Science and Technology Innovation Award of 2015 HLHL Foundation and was inducted as an Academician of the Chinese Academy of Engineering. In 2017, he was recognized with a National Innovation Competition Award, and with a Chinese Catalytic Achievement Award [29].

Liu Haichao (刘海超) was born in Henan Province on January 26, 1968. He received his B.S. degree in 1990 and M.S. degree in 1993 from Sichuan University with Prof. Li Xianjun, and his Ph.D degree from Beijing Research Institute of Petroleum Processing in 1996 with Prof. Min Enze. From 1997 to 2003, he worked as a Postdoctoral Research Fellow at the University of Tokyo with Iwasawa Yasuhiro and from 2000 to 2003 at the University of California at Berkeley with Professor Enrique Iglesia. See Figs. 64-65.

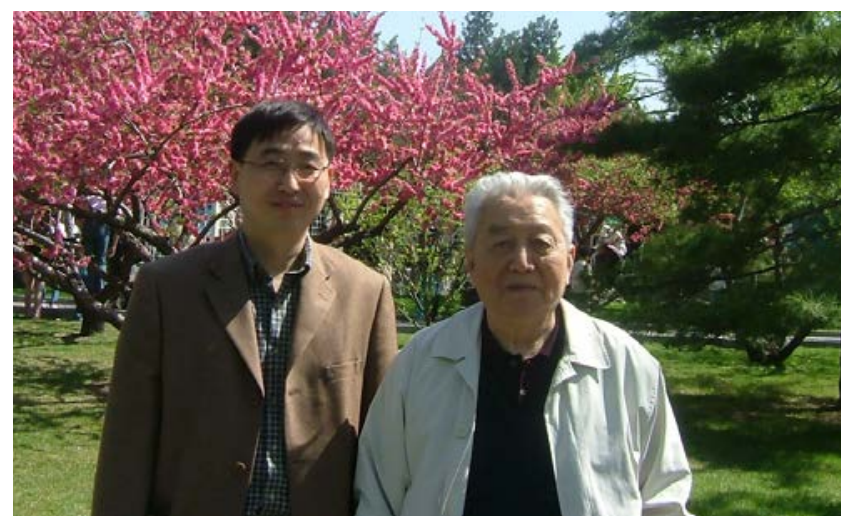

Fig. 65. At Zhongshan Park, close to Tiananmen in 2005. From left: Liu Haichao and Min Enze. Photo: Courtesy of Liu Haichao. 


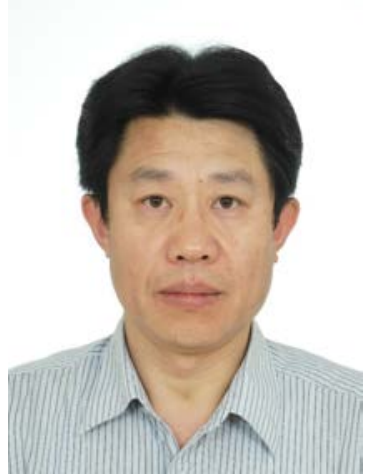

Fig. 66. Shen Wenjie (申文杰, 1966-). Photo: Courtesy of Yuan Youzhu.

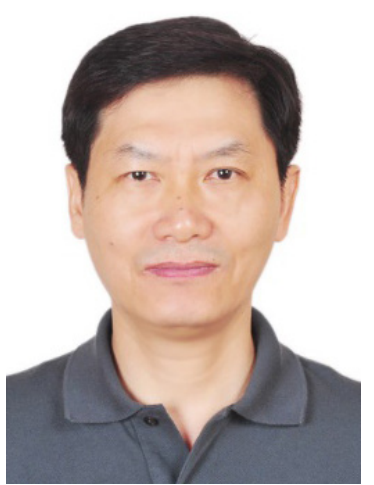

Fig. 67. Yuan Youzhu (袁友珠, 1963-).
Liu Haichao is currently Professor of Chemistry at Peking University and editor of the Journal of Catalysis. His research group works in the area of molecular catalysis and sustainable energy chemistry, mainly focusing on the fundamental studies of the catalyst structures and reaction mechanisms, towards the design of heterogeneous catalysts and control of reaction pathways for selective conversion of biomass and its derivatives to bulk and fine chemicals.

Shen Wenjie (申文杰, Fig. 66) was born in October 25, 1966 in Shanxi. He is currently the Director of the State Key Laboratory of Catalysis, at DICP, and the leader of the catalytic reaction chemistry group. In 1988, he obtained his B.S. from the China National University of Defense Technology, in 1991 a M.S. degree from Taiyuan University of Technology, and in 1995 his doctorate in engineering from the Shanxi Institute of Coal Chemistry, Chinese Academy of Sciences. From 1996 to 1998, he was a Postdoctoral Fellow at the Osaka Institute of Industrial Technology, Institute of Industrial Technology, Ministry of International Trade and Industry, Japan, and from 1998 to 2001 an Industrial Technology Researcher at the same Institute. In 2001, he was selected into the "Hundred Talents Program" of the Academy of Sciences of China.

Shen Wenjie is mainly engaged in the application of basic research of catalytic materials and catalytic reaction processes for the high activity, high selectivity and high stability of catalysts involved in important energy and environmental reactions, catalytic chemical preparation, structural regulation, reaction mechanism and kinetics the study. In recent years he has presided as chief scientist over one national major scientific and technological research plan. He has also been Project Leader for a project of the Ministry of Science and Technology 973 sub-project, six national fund projects, and international cooperation between BP and GM. He has received many honorary awards such as the Outstanding Youth Science Fund of the National Natural Science Foundation of China, the China Catalysis Youth Award of the Catalysis Committee of the Chinese Chemical Society, and the outstanding instructors of the Chinese Academy of Sciences [30].

\subsubsection{Chinese professors who were educated in Japan}

Yuan Youzhu (袁友珠, Fig. 67) was born on January 24, 1963. In 1990, he received a Dr. Eng. from Nanjing Forest University and in 2000 a Dr. Sci. from the University of Tokyo in 2000. From 1990 to 1992 he was a Postdoctoral Associate in the group of Prof. Tsai Khiirui (蔡启瑞) in Xiamen University. Shortly thereafter he became a faculty member of Xiamen University, and then from 1995 to 2000 he was a Visiting Scholar in Prof. Yasuhiro Iwasawa's group at Tokyo University and then a Japan Science and Technology Research Fellow. In 2000, he started his independent academic career in Xiamen University as a full Professor in the catalysis division of the Department of Chemistry. He also became a Senior Research Fellow in the State Key Laboratory of Physical Chemistry of Solid Surfaces, National Engineering Laboratory for Clean Productions of Alcohols-Ethers-Esters, and the Collaborative Innovation Center of Chemistry for Energy Materials (iChEM). He studies catalysis across heterogeneous and homogeneous systems, currently focusing on catalytic synthesis and transformation of non-petrol carbon resources. He has received several awards such as the second prize of natural sciences of Chinese Universities, the excellent and key teacher of MOE, the first prize of teaching achievements of Fujian Province, the second prize of teaching achievements of MOE [31].

He Hong (贺泓) was born on January 15, 1965 in Handan

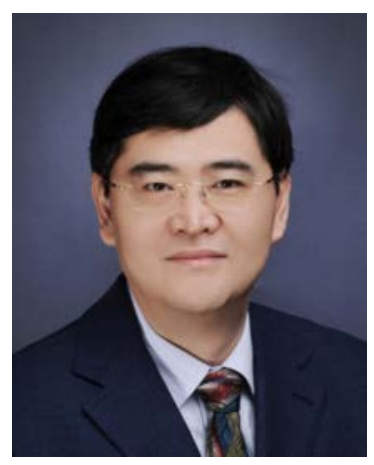

Fig. 68. He Hong (贺泓, 1965-) Photo: Courtesy of Yuan Youzhu. 


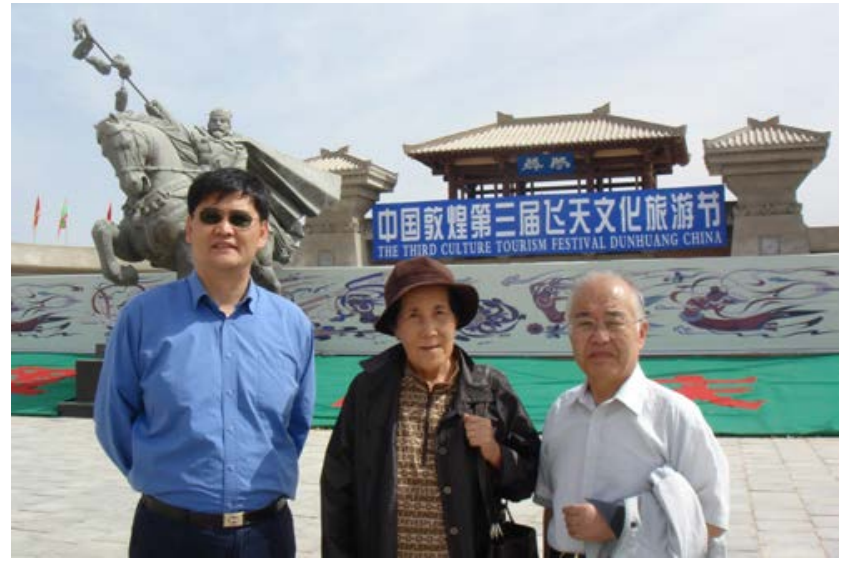

Fig. 69. Visiting China in 2006. He Hong (贺泓), Tanaka Masako, Tanaka Kenichi (田中虔一). Photo: Courtesy of He Hong.

City, Hebei Province. In 1994, he received his doctorate (Ph.D.) at the University of Tokyo with Prof. Tanaka Kenichi. He Hong worked in Japan, the United States and Canada for 11 years, and in 2001 joined the Research Center for Eco-Environmental Sciences, Chinese Academy of Sciences (RCEES-CAS) through the "Hundred Talents Program" of the CAS. He Hong is a Member of Chinese Academy of Engineering (CAE), Chief Scientist of the Center for Excellence in Regional Atmospheric Environment, and Deputy Director of the RCEES-CAS. His research has focused on basic and applied research in environmental catalysis and atmospheric chemistry, in areas of diesel emission control technologies, catalytic indoor air purification and haze formation mechanism. He is author of 363 peer-reviewed papers, inventor of 42 patents, 11 of which have been applied commercially, and author of a scholarly book (The Principles and Application of Environmental Catalysis) in Chinese. In 2011, he was awarded the National Technology Invention Award (China), in 2014 the National Science and Technology Progress Award (China) and in 2017 the Ho Leung Ho Lee Foundation Prize for Scientific and Technological Innovation. Prof. He presided over the 6th International Conference on Environmental Catalysis as co-Chairman in 2010, and he launched a series of China-Japan Workshops on Environmental

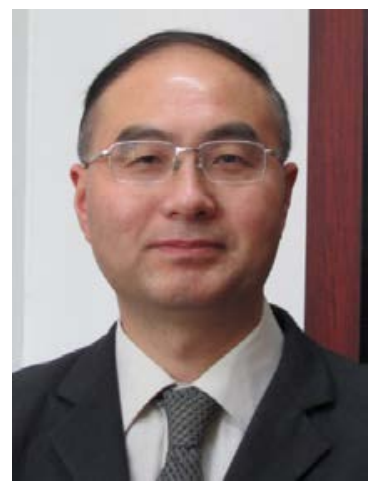

Fig. 70. Wang Ye (王野, 1966-) Photo. Courtesy of Yuan Youzhu.

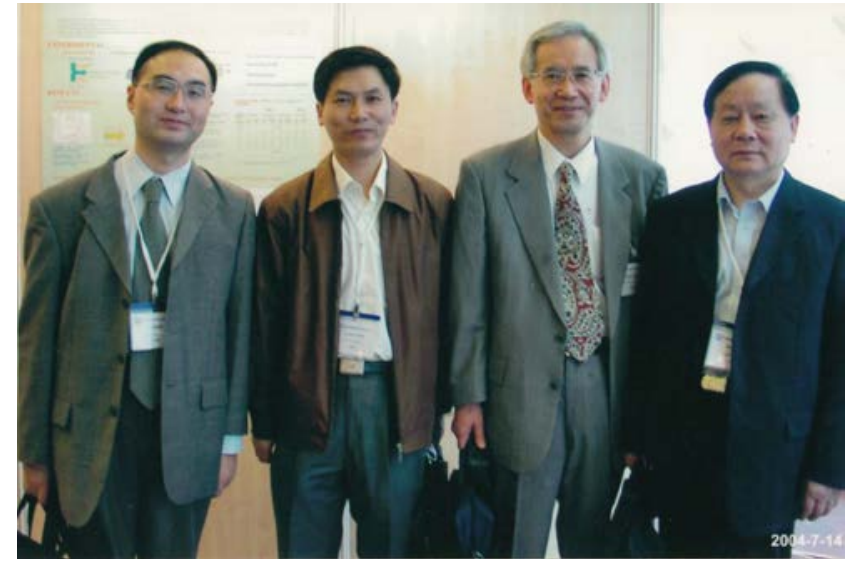

Fig. 71. Meeting in Xiamen 2004. From left: Wang Ye (王野), Yuan Youzhu (袁友珠), Iwasawa Yasuhiro (岩澤康裕), Wan Huiling (万惠霖). Photo: Courtesy of Iwasawa Yasuhiro.

Catalysis and Eco-materials as founder and organizer since 2003. See Figs. 68 and 69.

Wang Ye (王野) was born on May 25, 1966. In 1986, he graduated from Nanjing University and in 1996 obtained his Ph.D. degree from the Tokyo Institute of Technology, Japan with Otsuka Kiyoshi. From 1996 to 2000, he worked as research associate at the Tokyo Institute of Technology, at Tohoku University and at Hiroshima University all in Japan and in 2001 became Associate Professor at Hiroshima University. In August 2001, he became a full Professor of Xiamen University in the August of 2001 and is currently the Director of the State Key Laboratory of Physical Chemistry of Solid Surfaces at Xiamen University. Professor Wang received the Distinguished Young Scholar Fund from the National the Natural Science Foundation of China in 2006 and the Chinese Catalysis Society Award for Young Scientist in 2010. He has been an Associate Editor of ACS Catalysis since 2017 and is currently a member of the editorial boards of the Chinese Journal of Catalysis, the Journal of Energy Chemistry, Science China Chemistry and Applied Catalysis A: General. His research interests are catalysis for C1 and sustainable chemistry, including selective transformations of synthesis gas, methane, $\mathrm{CO}_{2}$ and biomass into chemicals and fuels [32]. See Figs. 70 and 71.

\subsubsection{Chinese professors who teach in Japan}

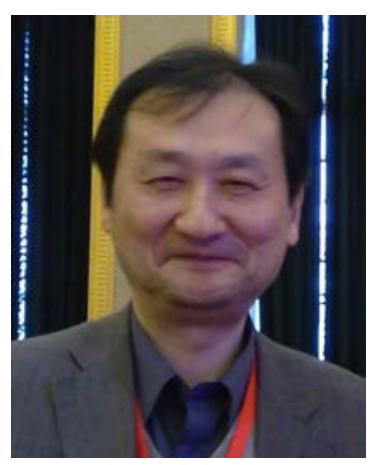

Fig. 72. Xu Qiang (徐强). 


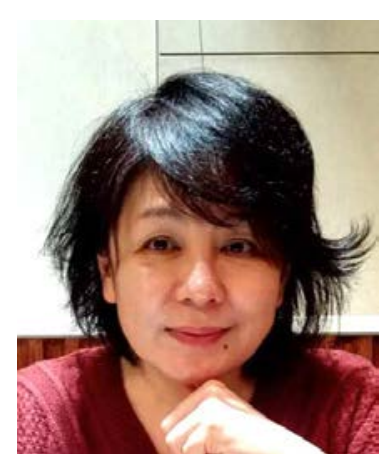

Fig. 73. Li Xiahong (黎晓红, 1960-).

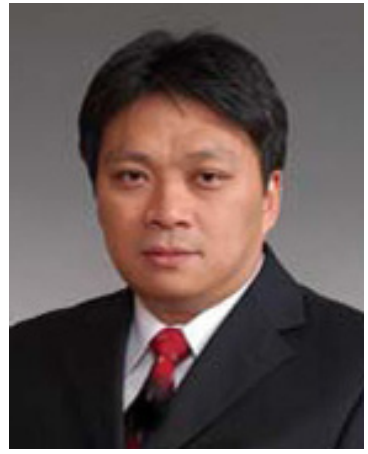

Fig. 75. Tsubaki Noritatsu (椿范立, 1965-).
Xu Qiang (徐强, Fig. 72) joined Osaka University in 1987, where he got his Ph.D. in Physical Chemistry (solid-state NMR studies) in 1994. After one year of postdoctoral research in the same university, in 1995 he joined the Osaka National Research Institute (ONRI), which was re-organized into the National Institute of Advanced Industrial Science and Technology (AIST), where he has worked until now. He is currently Director of AIST-Kyoto University Chemical Energy Materials Open Innovation Laboratory (ChEM-OIL) and holds Adjunct Professor Positions at Kobe University and Kyoto University. He has mainly worked on the chemistry of nanostructured materials and their applications, especially for catalysis and energy. He was guest professor of DICP, Zhejiang University, Jinan University and Tianjin University, and is now adjunct Professor of Yangzhou University and distinguished honorary Professor of Hong Kong Polytechnic University, China. He has supervised more than 40 Chinese Ph.D. students and postdoctoral fellows, many of whom are now working in China as Professors.

Li Xiahong (黎晓红, Fig. 73) was born in Dalian in August 1960. In 1982 she graduated from Liaoning Normal University and continued on as a lecturer until 1991. From 1992 to 1997 she was a Visiting Scholar at the University of Tokyo, and in 1996 she obtained her Ph.D. there with Fujimoto Kaoru. She continued as Researcher on a project funded by the New Energy Development Organization (NEDO) and in 2000 she ob-

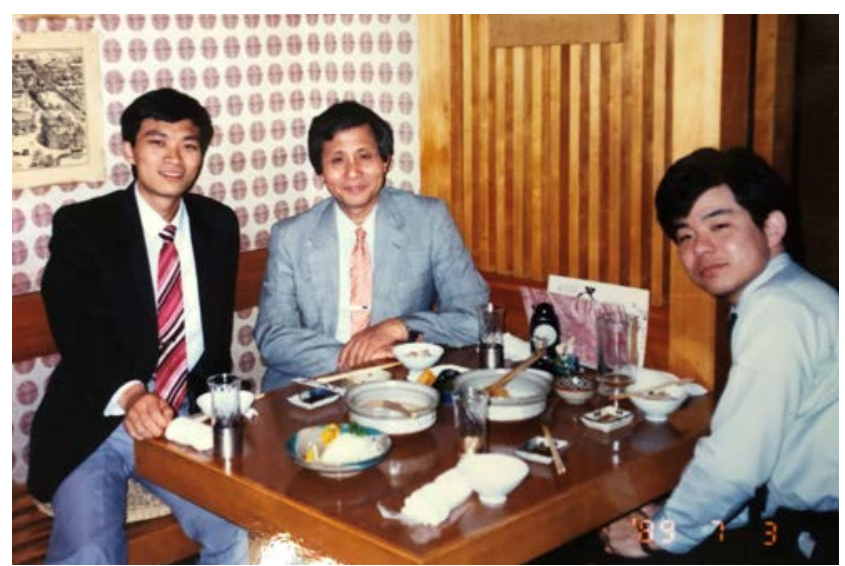

Fig. 74. China-Japan-USA Symposium on Heterogeneous Catalysis, Sapporo, July 1989. From left: Tsubaki Noritatsu, Fujimoto Kaoru, Yokota (Asahi Kassei). Photo: Courtesy of Tsubaki Noritatsu. tained a position as Associate Professor at Kitakyushu University. In 2007 she was promoted to Full Professor. Her fields of research are methane activation, biomass conversion, Fischer-Tropsch synthesis, hybrid and eggshell-type catalyst synthesis.

Tsubaki Noritatsu (椿范立) was born in August 2, 1965 in Changsha city, Hunan province. His original name was Fan Li ( 范立) and he became a naturalized Japanese by marriage. From 1982 to 1987, he studied in the Department of Chemical Physics (BS) of the University of Science and Technology of China (USTC, Hefei, Anhui) under the direction of Prof. Yilu Fu. In April 1992 he moved to the University of Tokyo, and got his doctoral degree in 1995 with Prof. Kaoru Fujimoto. In 1995, he became Assistant Professor and in 1998 Lecturer in the same laboratory.

In 2001, he became Professor at the University of Toyama, as the youngest full Professor in Catalysis Society of Japan. In 1993 Prof. Tsubaki was awarded the Prize of the Japan-China Sci. Tech. Association, in 1994 the Japan Industry Newspaper Prize, in 1998 the Noguchi Prize of the Japan Petroleum Institute, in 2000 the Progress Prize of the Japan Institute of Energy, in 2006 the Prize of JSPS (Japan Society for the Promotion of Science), and in 2017 the Award of the Japan Institute of Energy (2017). In 2017, he was elected as member of Science Council of Japan. See Figs. 74 and 75.

\section{About the author}

S. Ted Oyama (1955-, Fig. 76) was born in Tokyo, Japan on February 16, 1955. At two years old he was taken by his parents to South America, where he was raised in Argentina, Venezuela, and Brazil, so he is fluent in Spanish and Portuguese. In 1976 he obtained his M.S. degree in Chemistry from Yale University and in 1981 he earned his Ph.D. from Stanford University with Michel Boudart. In 1980 he was an exchange student in the laboratory of Tamaru Kenzi at the University of Tokyo, and in 1982 he married his daughter Hideko. In 1981, Ted Oyama worked as a Research Engineer at Catalytica, Inc. in Mountain View, Calif., and from 1986 to 1988 as an Industrial Postdoctoral Fellow in the laboratory of Gabor Somorjai. From 1988 to 1992, he was an Associate Professor at Clarkson University in Potsdam, NY, and then from 1992 to the present was Professor in the Chemical Engineering Department at Virginia 


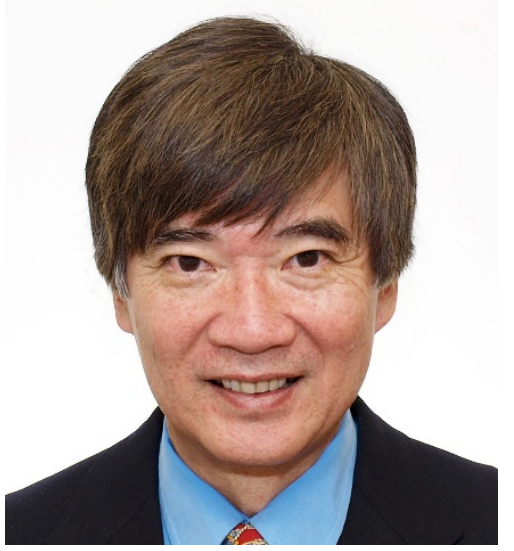

Fig. 76. Shigeo Ted Oyama (1955-).

Tech. In 2009, he became Professor in the Chemical Systems Engineering Department at the University of Tokyo, retaining his Virginia Tech association. In 2015, he became Minjiang Scholar Visiting Professor at Fuzhou University Ted Oyama received several honors including the 2009 Humboldt Senior Researcher Award and the 2016 American Chemical Society Storch Award. He was selected to be the 2020 Zhang Dayu lecturer at DICP.

This article was suggested to the author by Tao Zhang at the American Chemical Society meeting in Orlando, Florida in March 2019. The co-authors met in a planning meeting at DICP later that month (Fig. 77).

\section{Acknowledgments}

S. Ted Oyama greatly appreciates the help of Fang Kun, Hattori Hideshi, Morikawa Akira, Li Xiaohong, Shu Yuying and Aika Kenichi (秋鹿研一). Support is thankfully acknowledged to Fuzhou University for the Mingjiang Scholar Research Professorship.

\section{References}

[1] S. C. M. Paine, The Wars for Asia, 1911-1949. Cambridge: Cambridge University Press, Cambridge, 2012.

[2] Charles River Editors. The Japanese Invasion of Manchuria: The History of the Occupation of Northeastern China that Presaged World War II . Charles River Editors. Kindle Edition. p. 10.

[3] T. Toyoda, Hurst Cameron et al., Editors of the Encyclopaedia Britannica, June 20, 2019, https://www.britannica.com/place /Japan/The-emergence-of-imperial-Japan.

[4] Richard Linthicum, War between Japan and Russia ... with historical and descriptive sketches of Russia, Siberia, Japan, Korea and Manchuria, Chicago, Kindle Edition, 1904.

[5] https://dot.asahi.com/print_image/index.html?photo=20160527 00162_1.

[6] Tsuneya Marusawa, New China construction and Manchurian Railroad Central Research Laboratory, Nigatsusha, Tokyo, 1979.

[7] Nozomu Sugita, "Manchurian Railroad Central Research Laboratory" Men who made a dream on the continent, Kodansha Co., Ltd., Tokyo, 1990.

[8] Takeshi Mine, History of Industrialization in China-From the Perspective of Chemistry, Nippon Kinpo, 2017.

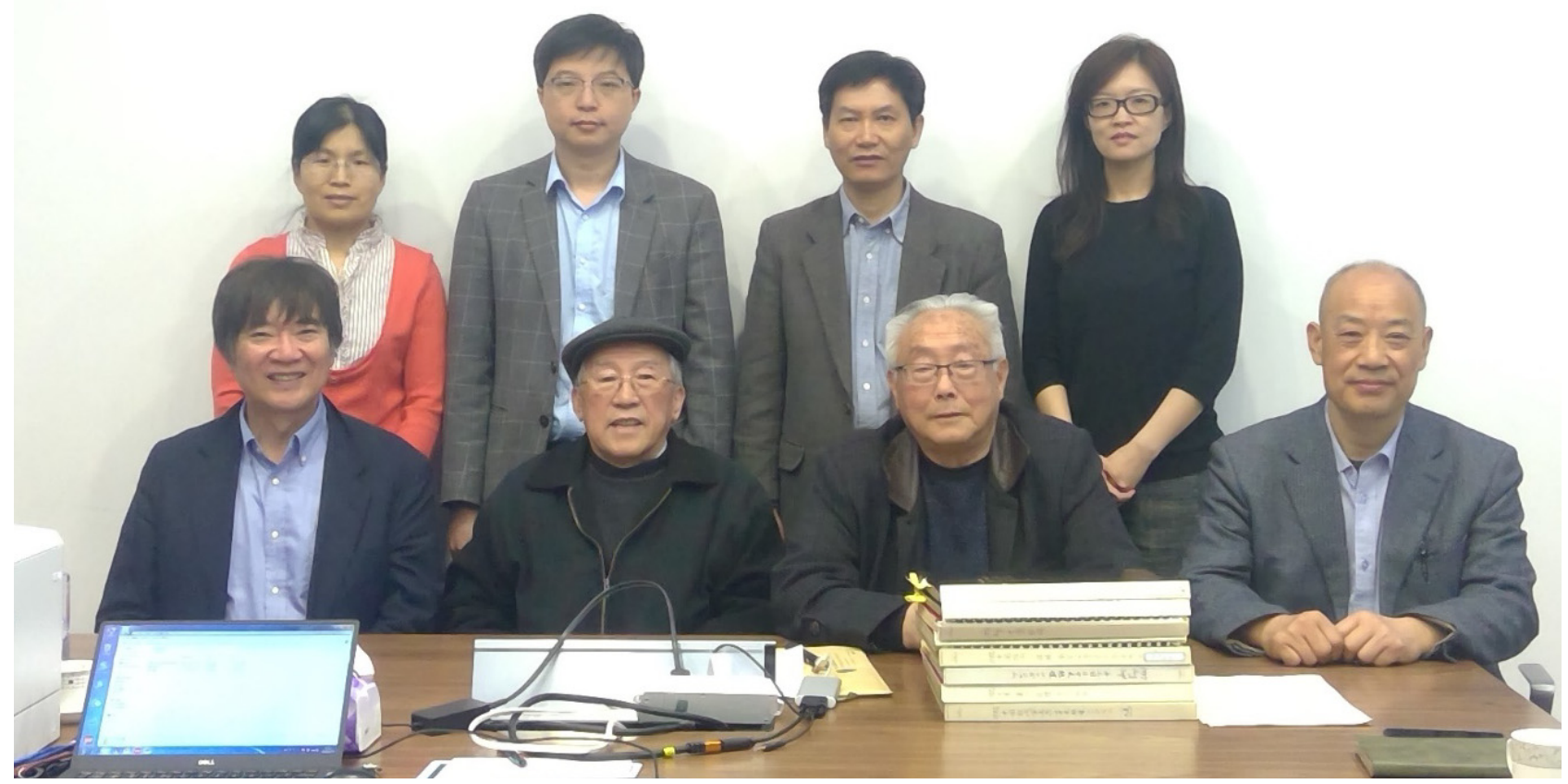

Fig. 77. Authors: Bottom from left: S. Ted Oyama, Xiong Guoxing (熊国兴), Xin Qin (辛勤), Xu Jie (徐杰). Top from left: Yin Hongmei (尹红梅), Zheng Huidong (郑辉东), Yuan Youzhu (袁友珠), Fang Kung (方掠). 


\section{Graphical Abstract}

Chin. J. Catal., 2019, 40: 1591-1614 doi: S1872-2067(19)63483-2

History of the Dalian Institute of Chemical Physics and the Friendship Between China and Japan in Catalysis

S. Ted Oyama * with Qin Xin, Guoxing Xiong, Wenjie Shen, Jie Xu, Hongmei Yin, Youzhu Yuan, Haichao Liu, Huidong Zheng

Fuzhou University, China;

The University of Tokyo, Japan;

Dalian Institute of Chemical Physics, Chinese Academy of Sciences, China;

Xiamen University, China;

Peking University, China

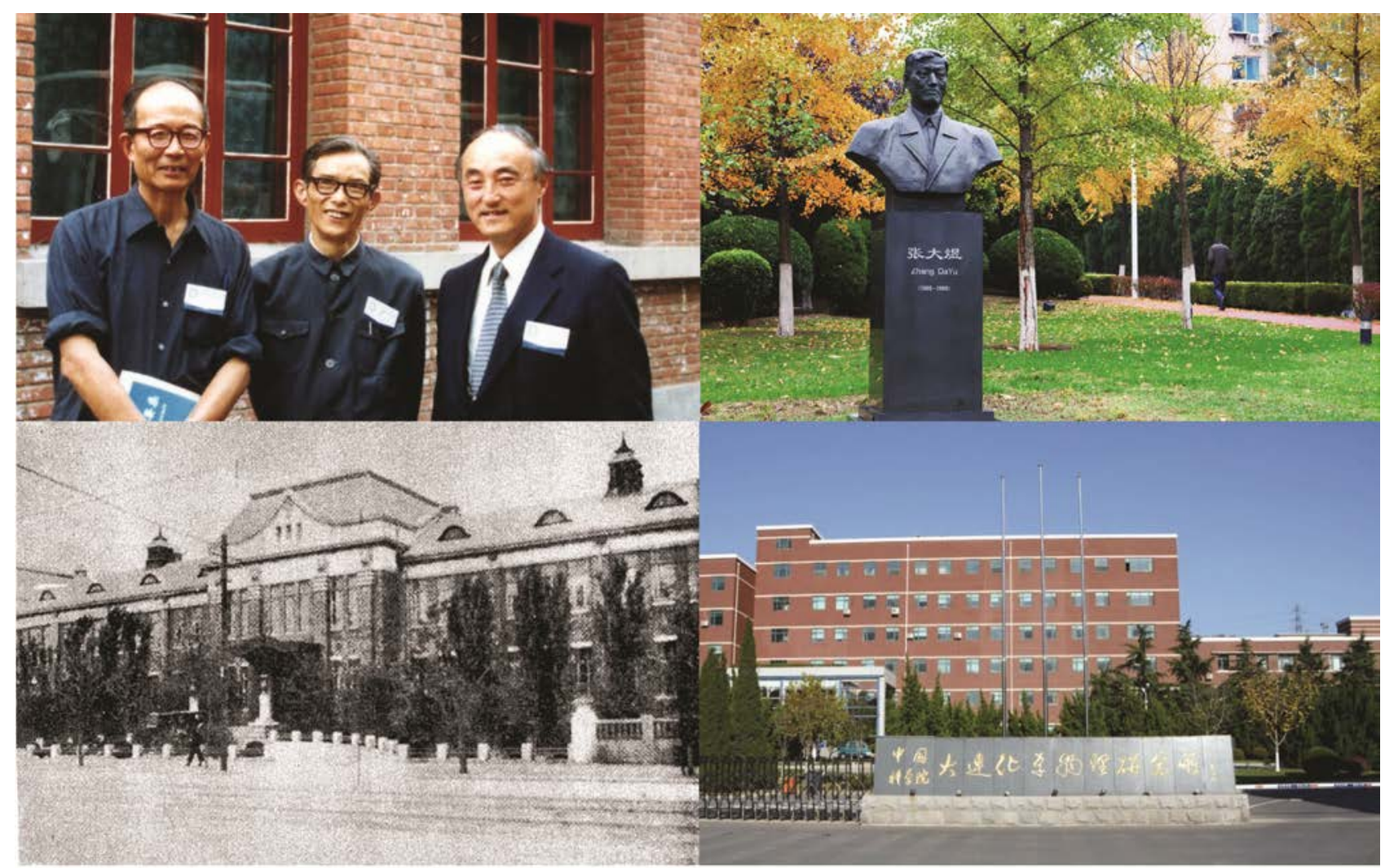

The year 2019 marks the $70^{\text {th }}$ anniversary of the beginning of the Dalian Institute of Chemical Physics, Chinese Academy of Sciences (Abbreviated as DICP). This article presents a history of the origins of DICP and relates the recent friendship between China and Japan in the field of catalysis.

[9] B. Liang, Why did the Japanese fail to find Daqing Oilfield, http://www1.ihns.ac.cn/readers/daqing.htm, 2007.

[10] https://kotobank.jp/word/丸沢\%20常哉-1655559.

[11] http://pekin-media.jugem.jp/?eid=2111 Talking about Maruzawa Tsuneya, "The Last Captain" of the Mantetsu Central Research Institute- Naoki Yamaguchi, President of the Japanese Academic Exchange Meeting in Beijing, Aug. 27, 2015, China News by Shaolin.

[12] http://pekin-media.jugem.jp/?eid=2111.

[13] Q. Xin, Y. X. Li, Chin. J. Catal., 2019, 40: 1615-1626.

[14] https://baike.baidu.com/item/张大煜.

[15] Rana Mitter. Modern China: A Very Short Introduction (Very Short Introductions), OUP Oxford., Kindle Edition, p. 62.

[16] Q. Xin, L. W. Lin, Chin. J. Catal., 2013, 34: 401-435.
[17] Akira Morikawa, Personal communication, April 2019.

[18] Kenzi Tamaru, Personal communication, May 2019.

[19] Kenzi Tamaru, Petrotech, 1981, 4(5): 38.

[20] Kenzi Tamaru, Personal blog, July 2019.

[21] Lanzhou Institute of Chemical Physics webpage, http://www.licp.cas.cn/sy2018/yjdw/yszj/ygys/201810/t20181 008_5138860.html.

[22] Hideshi Hattori, Personal communication, June 2019.

[23] http://nacatsoc.org/memorial/in-memoriam-kozo-tanabe-19262018/.

[24] EFCATS webpage https://efcats.org/Resources/Obituaries.html

[25] https://en.wikipedia.org/wiki/Min_Enze.

[26] Youzhu Yuan, Personal communication, July 2019.

[27] Xiaohong Li, Personal communication, July 2019. 
[28] https://www.journals.elsevier.com/chinese-journal-of-catalysis/ editorial-board/masatake-haruta.

[29] http://english.dicp.cas.cn/pe_17251/dp/.

[30] http://sourcedb.dicp.cas.cn/zw/zjrck/200908/t20090820_2428 041.html.
[31] https://www.journals.elsevier.com/chinese-journal-of-catalysis/ editorial-board/youzhu-yuan/.

[32] https://www.journals.elsevier.com/chinese-journal-of-catalysis/ editorial-board/ye-wang/. 